\title{
PhiMiSci
}

Philosophy and the Mind Sciences

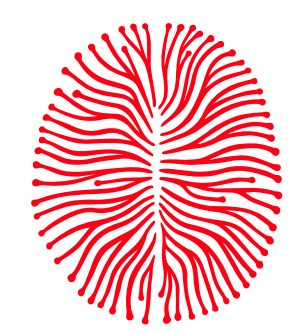

\section{Vicarious attention, degrees of enhancement, and the contents of consciousness}

\author{
Azenet Lopez ${ }^{\mathrm{a}}$ (D) (Lopez.Azenet@lrz.uni-muenchen.de)
}

\begin{abstract}
How are attention and consciousness related? Can we learn what the contents of someone's consciousness are if we know the targets of their attention? What can we learn about the contents of consciousness if we know the targets of attention? Although introspection might suggest that attention and consciousness are intimately connected, a good body of recent findings in cognitive psychology and cognitive neuroscience brings compelling reasons to believe that they are two separate and independent processes. This paper attempts to bring attention and consciousness back together to make the study of attentional distributions an essential ingredient for the study of the contents of consciousness. My proposal has two main components. First, I introduce a framework for systematizing the relations between attention in its different forms and consciousness in its different forms. Although philosophers and cognitive scientists have repeatedly highlighted the importance of such systematization, most details are still to be worked out. Here I take an initial stab at this project based on the notion of degrees of informational enhancement. Second, I introduce the notion of vicarious attention to account for a kind of additional processing benefit that comes for free when attention is allocated to a target. I then propose that this kind of processing must also be considered when mapping attention targets into contents of consciousness.
\end{abstract}

\section{Keywords}

Attention · Attentional blink $\cdot$ Consciousness $\cdot$ Motion-induced blindness $\cdot$ Troxler fading

\section{The explanatory project}

What is the relation between attention and consciousness? Can we learn what the contents of someone's consciousness are if we know the targets of their attention? What can we learn about the contents of consciousness if we know the targets of attention? The project of providing answers to these questions (in particular, an affirmative answer to the second one and a substantive answer to the third) is the explanatory project, that is, the project of using attention to contribute to our understanding of consciousness. ${ }^{1}$

${ }^{a}$ Ludwig Maximilian University of Munich, Germany

${ }^{1}$ Prominent theorists endorsing a project in this spirit include Prinz (2012) and Graziano (2013; 2019). 
The explanatory project is motivated by both pre-theoretical and theoretical considerations. Pre-theoretically, the things that fill in our conscious experiences in our everyday lives seem to follow closely the things we attend to. An experience of pain feels intensified when you focus your attention on the aching body part, and it feels lessened when you direct your attention away from it. Attending to the feeling of the floor against your feet seems sufficient for bringing this feeling to your conscious experience. It might also be necessary: before you directed your attention to your feet, the feeling of the floor was perhaps a very faint component of your overall conscious experience, if it was a part of it at all. ${ }^{2}$ These observations suggest that if we want to know the contents of someone's conscious experiences, all we need to do is look at the things they are attending to. ${ }^{3}$

There are also theoretical considerations that lead to treating attention as a guide to the contents of consciousness. One prominent example is the Attended Intermediate Representations theory of consciousness, articulated by the philosopher Jesse Prinz (2012). According to Prinz, empirical research reveals that the neuronal correlates and the functional roles of attention are intertwined with those of consciousness so that attention is both necessary and sufficient for consciousness. On this view, a conscious experience of a pain arises when and only when a representation of that pain is modulated by attention. ${ }^{4}$ Another prominent example is the Global Workspace Theory (Baars, 2002, 2005; Dehaene \& Naccache, 2001). On this theory, for you to have a conscious experience of a pain is for information of that pain to become globally available. This means that information must be encoded by central cognitive mechanisms integrating inputs from different processing channels, including channels that process different kinds of sensory and proprioceptive information. Attention to the relevant information is necessary and sufficient for it to become thus available. If theories like Global Workspace and Attended Intermediate Representations are on the right track, attention turns out to be the key to understand consciousness.

However, a wealth of recent findings in cognitive psychology and cognitive neuroscience strongly suggests that attention and consciousness are, in fact, two

\footnotetext{
${ }^{2}$ Eric Schwitzgebel (2007) conducted a retrospective sampling study to assess whether participants had this form of peripheral and subtle experiences when they were not attending, especially in the visual and tactile modalities. He gave participants a beeper that would randomly go off and instructed them to note the experiences they were having immediately before hearing the beep. Results were mixed: they did not conclusively favor a thin view (according to which we never have these experiences) nor a rich view (according to which these experiences are pervasive). Instead, the data pointed to a moderate view: we likely experience some things outside the focus of attention. The proposal I develop in this paper also takes this moderate stance. I am thankful to Jennifer Windt for bringing this study to my consideration.

${ }^{3}$ For interesting surveys of commonsense intuitions about the relations between attention and consciousness, see Mole (2008b), De Brigard (2010).

${ }^{4}$ This is a simplification of Prinz's proposal. On his view, the representation is of a particular kind, namely, a representation at the intermediate level in the hierarchy of perceptual processing. Two controversial tenets of Prinz's account that I cannot discuss here are that all consciousness is located at this intermediate level, and that all consciousness is perception-based.
}

Lopez, A. (2022). Vicarious attention, degrees of enhancement, and the contents of consciousness. Philosophy and the Mind Sciences, 3, 1. https://doi.org/10.33735/phimisci.2022.9194 
separate and independent processes. This might further suggest that attention does not really stand in a privileged relation to consciousness. If so, then the study of attention cannot really offer us a unique window into consciousness. Studying attention would then be no more relevant for understanding consciousness than studying other mental processes.

This paper attempts to bring attention and consciousness back together so that the study of attention remains an essential ingredient for the study of the contents of consciousness. In a nutshell, I will argue that the picture of attention and consciousness currently given by the empirical sciences does still support the existence of tight and essential connections between their underlying processes. I propose that if attention is understood as an informational enhancer (a characterization strongly suggested by the way attention is conceptualized and operationalized in the empirical literature), it is possible to systematically map different forms of attention into different forms of consciousness by looking at the degree to which the relevant information is enhanced.

Here is the plan for what follows. Sections 2 and 3 are mostly stage-setting. In section 2, I clarify the notions of attention and consciousness and pin down the kinds this paper addresses more directly, namely, selective attention and phenomenal consciousness. I also review some empirical findings that have been taken to support a tight connection between attention and consciousness of these kinds. In section 3, I review some of the most prominent empirical findings evincing a dissociation between attention and consciousness and point at the specific ways how these findings could jeopardize the explanatory project. Together, sections 2 and 3 give a general sense of our current empirical picture of the relations between attention and consciousness. Section 4 is a bridging one, where I introduce the main lines of my positive proposal, explain how it fits into our empirical picture, and identify potential difficulties. The most substantive discussion comes in sections 5 and 6. In section 5, I discuss the core of the proposal, namely, the enhancement framework. I elaborate on some of its central notions, compare it with other akin approaches, and defend it from initial empirical objections. I also identify a crucial assumption for defusing the discussed counterexamples: the claim that when attention is allocated to a target, the elicited processing benefits often extend to other things beyond the selected target. In section 6, I introduce the term "vicarious attention" to refer to this kind of processing, and I offer some initial conceptual and empirical reasons for believing that attention does behave in this way.

\section{Selective attention as a window into phenomenal consciousness}

"Attention" and "consciousness" are terms that pick out a variety of related yet distinguishable kinds of processing. This paper focuses on phenomenal consciousness, the kind of consciousness constituted by the subjective experience in which

Lopez, A. (2022). Vicarious attention, degrees of enhancement, and the contents of consciousness. Philosophy and the Mind Sciences, 3, 1. https://doi.org/10.33735/phimisci.2022.9194

() (1) (c) The author(s). https://philosophymindscience.org ISSN: 2699-0369 
the world appears to us in a certain way, and which is characterized by its what-itis-like qualities (Block, 1995; Nagel, 1974). ${ }^{5}$ In this sense, for you to be conscious of a pain is for there to be something it is like for you to feel that pain, to experience a specific qualitative character. Notice that if we are concerned with this kind of consciousness, then a theory like Global Workspace might not turn out to be relevant (but see Raffone \& Pantani, 2010). Global Workspace theory rather seems to concern consciousness of another familiar kind, namely, access consciousness. This kind of consciousness is defined by its functional role in the processing of information. It is characterized by the subject's cognitive access to the experienced contents, which enables them to report these contents (Block, 1995). ${ }^{6}$ Phenomenal consciousness must also be distinguished from consciousness of a third important kind, namely, reflective consciousness. This kind of consciousness involves internal monitoring and self-awareness, that is, awareness of one's conscious states (Carruthers, 2000; Lycan, 1996; Rosenthal, 1997). At least conceptually, neither reflective consciousness nor access consciousness entails phenomenal consciousness, and phenomenal consciousness entails neither.

Regarding attention, here I adopt a characterization that is fairly standard amongst empirical researchers. I take attention to be a process involving the selection of a subset of the available sensory information for preferential processing, a mental focus in a particular aspect of information, and the prioritization of some parts of the information that is available at any given moment (Carrasco, 2011; Desimone \& Duncan, 1995; Posner, 1980; Cohen et al., 2012; Maier \& Tsuchiya, 2021; Naghavi \& Nyberg, 2005; Nani et al., 2019; see also Pitts et al., 2018). Nevertheless, we must note that this characterization only pins down a specific kind of attention, namely selective attention. There are other kinds of attentional processing that are not selective in any straightforward sense, for instance, distributed or diffuse attention. In addition, more general and global processes like those related to alertness and arousal are also sometimes counted as members of the attentional family (Petersen \& Posner, 2012; Posner \& Petersen, 1990).

Importantly, we must note that selective attention can also be of different types. It can be voluntary and controlled, guided by the subject's goals and task demands, or it can be involuntary and automatic, driven by stimulus salience and environmental conditions. In what follows, I refer to these varieties as endogenous and

\footnotetext{
${ }^{5}$ Most of the empirical literature discussed in this paper explicitly states the purpose to address this kind of consciousness Nani et al. (2019).

${ }^{6}$ Access consciousness is sometimes defined in terms of attention. For example, Daniel Stoljar (2019) proposes that for content to be conscious in this sense, it must be poised for use in the rational control of thought and action, and it must be thus poised because it has been attended. Although this view entails the dependence of access consciousness on attention, it does not need to entail the same for phenomenal consciousness. The moral is that attention might be necessary for some forms of consciousness but not for others. More precisely: some forms of attention might be necessary for some forms of consciousness, as we will see below. I thank an anonymous referee for prompting me to make this clarification.
}

Lopez, A. (2022). Vicarious attention, degrees of enhancement, and the contents of consciousness. Philosophy and the Mind Sciences, 3, 1. https://doi.org/10.33735/phimisci.2022.9194 
exogenous attention, respectively. Finally, selective attention can also be spatial, feature-based, or object-based. Each of these varieties gives rise to different profiles of processing advantages.

Note that this characterization is neutral as to whether the selection and prioritization of information are accessible at the personal level and reportable by the subject. This characterization is thus compatible with sub-personal selection and prioritization that is not accessible and reportable. In this way, attention is characterized as a process that, in principle, can occur with or without subjective awareness, and consequently with or without phenomenal consciousness. ${ }^{7}$

What is, then, the relation between selective attention and phenomenal consciousness? Can we learn about the things that constitute the contents of an organism's subjective experience of the world if we know which subset of information is selected and prioritized for preferential processing within their cognitive economy? What can we learn about the contents of an organism's subjective experience of the world if we know which subset of information is selected and prioritized for preferential processing?

Our answers to the second and third questions depend to a good extent on our answer to the first question. Furthermore, one might think that our ability to provide interesting answers to the second and third questions hinges on a tight connection between selective attention and phenomenal consciousness. A natural line of thought is: if attention and consciousness are very tightly connected so that they always co-occur, then attention can be used as a window into consciousness because the contents of conscious experience will always be identical to the targets of attention. One might also think that if attention can be used as a window into consciousness at all, then attention and consciousness must be very tightly connected so that they always co-occur.

Indeed, a good body of empirical findings lends initial support for the existence of such an intimate connection. On the behavioral front, studies on inattentional blindness strongly suggest that we fail to see stimuli we do not attend to (Mack \& Rock, 1998; Simons \& Chabris, 1999). In recent years, these results have been extended to properties that were initially thought to be immune to the effect, including the gist of a scene (Cohen et al., 2011; Li et al., 2002; Mack \& Clarke, 2012), statistical scene properties (Jackson-Nielsen et al., 2017) ${ }^{8}$ and even highly meaningful stimuli, like faces or one's own name (Devue et al., 2009). A variant of inattentional blindness is change blindness: major and meaningful changes in a scene can go unnoticed when attention is drawn away from them (Rensink et al., 1997; Tse, 2004; Wolfe et al., 2006). It has also been observed that when a stimulus

\footnotetext{
${ }^{7}$ This is an important point for the present discussion, for some might define attention as conscious selection and prioritization of information. This view seems implied by William James' (1890) celebrated characterization of attention as a concentration and focalization of consciousness, and more recently, by Declan Smithies' (2011). I thank an anonymous reviewer from this journal for prompting me to make this clarification

${ }^{8}$ Contra Bronfman et al. (2014); Block (2014).
}

Lopez, A. (2022). Vicarious attention, degrees of enhancement, and the contents of consciousness. Philosophy and the Mind Sciences, 3, 1. https://doi.org/10.33735/phimisci.2022.9194

(c) (1) () The author(s). https://philosophymindscience.org ISSN: 2699-0369 
captures attention, a second stimulus rapidly following it often goes unseen; this phenomenon is known as the attentional blink (Chun \& Potter, 1995; Raymond et al., 1992). Attention also has various measurable effects on conscious perception. For example, attending to a stimulus increases its perceived contrast, brightness, size, distance, speed, or direction of motion (Carrasco et al., 2004; Carrasco \& Barbot, 2019). Relatedly, visual sensitivity decreases when attention is distracted; this effect is known as load-induced blindness (Macdonald \& Lavie, 2008).

There is also neuroscientific data suggesting a close link between attention and consciousness. Famously, cases of hemispatial neglect reveal that damage to brain areas related to attentional processing is accompanied by impairments in conscious perception (Driver, 1998). Relevant brain areas are located in the frontal and parietal cortices, suggesting that frontoparietal involvement is required for attentional and conscious processing. In addition, sub-cortical areas like the pulvinar nucleus of the thalamus have been associated with filtering information on the one hand and with the level of consciousness on the other (Corbetta \& Shulman, 2002; Nani et al., 2019; Zhao et al., 2019).

It has also been observed that both attention and consciousness involve common ways of information processing in the brain. Prominently, they both have been linked to the amplification of neural signals and oscillatory synchrony. A variety of techniques, including single-unit recording, electroencephalography (EEG), and functional magnetic resonance imaging (fMRI), have revealed that attention amplifies signals from targets (Corbetta \& Shulman, 2002; Desimone \& Duncan, 1995; Kastner \& Ungerleider, 2000; Luck et al., 2000; Raz \& Buhle, 2006; Reynolds \& Chelazzi, 2004; Treue, 2003). These techniques have also revealed that attention actively suppresses signals from distractors (Andersen \& Müller, 2010; Chelazzi et al., 1993; Hopf et al., 2006; Luck et al., 1997; Moran \& Desimone, 1985; Reynolds et al., 1999; Thut et al., 2006; Vanduffel et al., 2000; Worden et al., 2000). In turn, activity in sensory regions has been observed to be greater when stimuli are consciously perceived, as opposed to not perceived (Dehaene et al., 2001; Haynes et al., 2005; Hesselmann et al., 2011; Polonsky et al., 2000; Ress et al., 2000; Ress \& Heeger, 2003; Sergent et al., 2011; Tong et al., 1998; Tse et al., 2005; Vuilleumier et al., 2001). Finally, both attention and consciousness have been observed to correlate with synchronic oscillatory activity, especially on the gamma frequency band. Synchrony between neurons and between populations of neurons seems to be an efficient way how brain regions encoding different bits of information can communicate with each other in order to create the unified percepts that constitute our conscious experiences of things in the world (Engel \& Singer, 2001; Singer \& Gray, 1995). Synchronic gamma activity in the visual cortex differentiates seen from unseen stimuli Wyart \& Tallon-Baudry (2009). This kind of correlation has been observed in a variety of paradigms, including masking (Melloni et al., 2007), bistable perception (Doesburg et al., 2005), and flash suppression in monkeys (Wilke et al., 2006), as well as in modalities other than vision (Gross et al., 2007). In turn, synchrony has been considered a way 
the selective filtering associated with attention is implemented, insofar as it generates windows of increased or decreased excitability (Buzsáki \& Draguhn, 2004; Steriade et al., 1993; Womelsdorf \& Fries, 2007). A neural population that is not synchronized to another will most likely fail to transmit its signal within the timeframes for optimal processing (Fries, 2005). Attention has also been observed to enhance gamma-band oscillations with a variety of experimental paradigms in monkeys and humans (Bauer et al., 2006; Engell \& McCarthy, 2010; Fries et al., 2001; Gruber et al., 1999; Tallon-Baudry et al., 1997; Tallon-Baudry et al., 2005; Vidal et al., 2006).

Findings like these suggest that (1) there is an intimate relation between attention and consciousness, which can be either a one-way or a two-way dependence, and which perhaps ultimately boils down to identity, (2) yes, knowing which subset of information is selected and prioritized for further processing is sufficient for knowing what the contents of someone's consciousness are, and (3) by knowing what information is selected and prioritized we know exactly what the contents of consciousness are.

Alas, the road from attention to consciousness is not that straightforward. On the one hand, almost all these findings have been contested, and there are ongoing debates about what the relevant data proves. One salient example concerns inattentional blindness and its variant change blindness: it has been proposed that these experiments could involve failures of memory rather than failures of conscious perception, so that unattended stimuli are seen but quickly forgotten $(\mathrm{Wu}, 2014)$. Another prominent example concerns frontoparietal involvement: these brain areas could be required for reporting conscious experience and not for conscious experience itself (Nani et al., 2019; Tallon-Baudry, 2012). Accordingly, hemispatial neglect can be reinterpreted as a case of inaccessible or non-reportable conscious experience. ${ }^{9}$ Finally, oscillatory synchrony could be a general information code in the brain, usable by any cognitive function including but not limited to attentional and conscious processing (Tallon-Baudry, 2012).

On the other hand, there is also an overwhelming amount of empirical and theoretical support for the idea that selective attention and phenomenal consciousness are rather independent of each other (Haladjian \& Montemayor, 2015; Maier \& Tsuchiya, 2021; Montemayor \& Haladjian, 2015; Tallon-Baudry, 2012; TallonBaudry et al., 2018; Van Boxtel et al., 2010b). I will now provide an overview of this evidence.

\footnotetext{
${ }^{9}$ In support of this interpretation, split-brain cases suggest that there might be separate streams of consciousness within the same brain. Usually, only the stream connected to the brain's language center can be verbally reported on, but other measures can be designed to tap into the other stream (for instance, reporting by drawing). See Volz \& Gazzaniga (2017).
} 


\section{A dissociation on three fronts}

Current grounds in favor of a dissociation between phenomenal consciousness and selective attention span three prominent fronts: behavioral, neuroscientific, and evolutionary. Behavioral studies suggesting a dissociation between the contents of phenomenal consciousness and selective attention have been further supported by neuroscientific studies relying on diverse techniques. fMRI, EEG, magnetoencephalography (MEG), and single-unit recording evince different neural correlates for selective attention and conscious perception (Maier \& Tsuchiya, 2021; Van Boxtel et al., 2010b). Moreover, as pointed out above, findings previously taken to reveal common neural correlates for attention and consciousness have recently been re-assessed in the light of further empirical findings, methodological refinements, and more finely-grained conceptual distinctions (Tallon-Baudry, 2012; Tallon-Baudry et al., 2018). Finally, it has been argued that attention and consciousness must diverge because anatomical and functional considerations suggest that they have evolved separately: while attention seems to be an early adaptation already present in very simple organisms, consciousness appears much later in evolutionary history, and only in organisms with a certain level of cognitive sophistication (Haladjian \& Montemayor, 2015; Montemayor \& Haladjian, 2015; see also Graziano, 2013).

In what follows, I present a somewhat more detailed yet quick survey of some relevant research. I sort it out into four groups: attention in the absence of consciousness, consciousness in the absence of attention, independence of both kinds of processing, and opposing functions and effects of the two of them. This survey admittedly fails to be comprehensive and to make full justice to all the arguments involved. Still, it can lend us a good sense of the empirical grounds for considering attention and consciousness as independent processes.

\subsection{Attention without consciousness}

Behavioral studies using a masked priming paradigm have shown that subjects can attend to a feature of a stimulus (for instance, color) without having seen either the stimulus or the feature (Ansorge et al., 2010; Kentridge et al., 2008; Kiefer \& Martens, 2010; Scharlau, 2002; Scharlau \& Ansorge, 2003; Scharlau \& Neumann, 2003). Furthermore, a combination of this technique with a paradigm for testing object-based attention (Egly et al., 1994; Kahneman et al., 1992) has been used to show that subjects can attend to objects that they cannot see Norman et al. (2015). Notably, the cues used to direct attention in these studies were fully visible. However, it has been shown that attention can be manipulated with invisible cues as well (Fuchs et al., 2013; Kim \& Blake, 2005). Moreover, even "high-level" properties such as being male or female can capture attention despite being invisible (Jiang et al., 2006).

At the intersection of cognitive psychology and the neurosciences, it has been observed that patients with blindsight, who have impaired or severely degraded

Lopez, A. (2022). Vicarious attention, degrees of enhancement, and the contents of consciousness. Philosophy and the Mind Sciences, 3, 1. https://doi.org/10.33735/phimisci.2022.9194

(9) (1) (c) The author(s). https://philosophymindscience.org ISSN: 2699-0369 
visual experiences due to damage in their primary visual cortex, are still able to effectively use visual attentional cues to detect targets in their blind field (Kentridge et al., 1999; Kentridge et al., 2008; Kentridge, 2011; Schurger et al., 2008). Also, studies probing the tilt-aftereffect for seen and unseen adaptor stimuli have shown that both can be modulated by either spatial (Bahrami et al., 2008) or feature-based attention (Kanai et al., 2006), with stronger effects elicited for attended adaptors. Furthermore, fMRI has revealed increased attention-related processing in the parts of the visual cortex that encode unseen stimuli on dual-task (Bahrami et al., 2007) and binocular suppression paradigms (Watanabe et al., 2011). Also, priming effects on event-related potentials can be enhanced by attention even when the prime is not consciously seen (Kiefer \& Brendel, 2006).

So attention can operate in the absence of awareness of the attended targets. This tells us that knowing that someone is attending to something still leaves it open whether they have a conscious experience of that thing. Thus, for the explanatory project to work, we need to address the question: when is selective attention accompanied by phenomenal consciousness? Is there a systematic way to pin this down? Are there common features that group together all instances of phenomenally unconscious selective attention, on the one hand, and all instances of phenomenally conscious selective attention, on the other? ${ }^{10}$ My proposal in section 5 attempts to answer these questions.

\subsection{Consciousness without attention}

On the behavioral front, studies of iconic memory with the partial report paradigm suggest that it is possible to experience many more elements from a visual scene than those picked up for report by selective attention (Block, 2007, 2008; Landman et al., 2003; Sperling, 1960). In addition, studies with a dual-task paradigm suggest that it is possible to have conscious experiences of elements in a visual scene outside the focus of attention, including natural scenes and animals (Li et al., 2002) and faces (Reddy et al., 2004, 2006). ${ }^{11}$ Finally, studies of visuospatial crowding suggest that it is possible to have conscious experiences of things one cannot attend to because the grain of attentional selection seems to be coarser than the grain of visual spatial resolution (Block, 2012; Intriligator \& Cavanagh, 2001; Pelli, 2008). ${ }^{12}$

\footnotetext{
${ }^{10}$ As noted below (section 5), a second important factor is stimulus strength (Braun, 2007; Dehaene et al., 2006; Pitts et al., 2018).

${ }^{11}$ See also Matthews et al. (2018).

${ }^{12}$ To be sure, there is controversy about what the results of partial report, dual-task, and crowding studies show. Besides the methodological challenges mentioned below, alternative accounts of the findings are available, which do not require phenomenal consciousness of the relevant stimuli. For example, Henry Taylor and Bilge Sayim (2018) argue that participants in the crowding experiments infer rather than see the identity of the middle items, based on the information they pick up from the flankers in conjunction with an assumption of homogeneity. Along similar lines, an anonymous reviewer for this journal has suggested that the predictive nature of perception could explain this performance. Predictive processing theorists propose that conscious percepts
} 
These behavioral results have been further supported by neuroscientific research. For instance, for the dual-task paradigm, fMRI reveals an increased response in the brain's fusiform face area, relative to baseline, for pictures of faces presented in the periphery (Reddy et al., 2007). This activity was independent of whether participants were fully attending to the faces or not, thus suggesting that perception of faces could occur with or without attention. ${ }^{13}$

However, the findings in this group face a critical methodological challenge: to date, there are no straightforward methods for testing consciousness that do not do it by means of attention. Paradigms designed for assessing consciousness typically rely on a task that requires that stimulus to be consciously perceived. However, participants will likely allocate at least some attention to any task-relevant stimulus (Cohen et al., 2012). Furthermore, reporting whether a stimulus was seen or not requires participants to attend to the stimulus. In other words, even if the stimulus was consciously seen before participants selected it for report, report-based methods cannot tap into this consciousness without thereby "contaminating" it with attention, so that what ends up being tested is no longer an unattended conscious content $(\mathrm{Wu}, 2018)$. To be sure, this is also a problem for the studies that purportedly evince the dependence of consciousness on attention, such as inattentional blindness and change blindness studies: by removing attention from the stimuli of interest, the means for assessing whether that stimulus is consciously perceived are removed as well (Stazicker, 2011; Wu, 2017).

To overcome these challenges, behavioral researchers have proposed new methods such as no-report paradigms (Tsuchiya et al., 2015) and paradigms that test the visibility or invisibility of task-irrelevant stimuli (Pitts et al., 2018). It has also been proposed that behavioral methods are not likely to be up to the task, and that the methodological disentanglement of attention and consciousness will probably have to be done with neuroscientific tools, such as optogenetics (Van Boxtel et al., 2010b). I find the latter approach highly congenial. The positive proposal offered in section 5 goes along these lines.

result from the brain's best predictions about the cause of an incoming sensory signal (Clark, 2013). Thus, in the face of a noisy signal from the middle stimulus, the brain might take its best guess about the stimulus's identity. If this is the case, one might wonder whether participants genuinely have a conscious experience of the middle item rather than an illusory one.

${ }^{13}$ Note, however, that there is conflict in the interpretations of the crucial finding in the dual-task paradigm, namely, that participants can use information from stimuli outside their focus of attention to complete a task. The studies described in this section treat these peripheral stimuli as consciously seen but unattended. However, as we saw in section 3.1, these stimuli are sometimes treated as attended but unseen (Bahrami et al., 2007). My proposal (in section 5) is to treat these stimuli as both attended and consciously seen, albeit to lessened degrees than the stimuli in the central task. 


\subsection{Opposite functions and effects}

In addition to the studies suggesting that consciousness might neither require nor be required for attention, a dissociation between attention and consciousness has also been proposed on the basis of general function. As a selective process, attention is often conceptualized as a mechanism for analyzing and filtering information (Van Boxtel et al., 2010b). In contrast, it is not clear what the function of consciousness is or whether it even has a function (Block, 1995; Haladjian \& Montemayor, 2015). Nonetheless, when functionally characterized at all, consciousness is regarded as a more integrative and synthetic process (for instance, see Tononi et al., 2016).

Other research shows that even in cases when attention and consciousness do subserve the same task-specific function, they do so in different ways. For example, although manipulations of attention and consciousness both strengthen priming effects, attending to the prime does so by speeding up reaction times to congruent targets, while increasing the prime's visibility does so by slowing down reaction times to incongruent targets (Van den Bussche et al., 2010).

More strikingly, some studies have suggested that attention and consciousness sometimes have opposing effects, so that attention sometimes seems to impair consciousness. It has been observed that attention can diminish the intensity of perceptual experience (De Weerd et al., 2006). In a motion-induced blindness paradigm, where a salient stimulus is rendered invisible by a surrounding cluster of moving dots, purposefully attending to the stimulus makes it more likely to disappear (Geng et al., 2007; Schölvinck \& Rees, 2009). The effect is greater for more salient stimuli (Bonneh et al., 2001). Similarly, attention can accelerate the Troxler fading effect: while holding fixation, some peripheral stimuli disappear faster when attention is directed to them (Lou, 1999). ${ }^{14}$ Finally, distracting attention from the target stimuli in the attentional blink paradigm makes it easier to see the second target, which is missed when attention is fully engaged on the detection task (Olivers \& Nieuwenhuis, 2005).

These findings tell us that attention and consciousness are not identical at the level of brain mechanisms or computational functions. Furthermore, they tell against the idea that attentional processing is in the business of improving conscious perception, and that the former might be required for the latter: the studies suggest that sometimes one can only have a conscious experience of something if one is not attending to it. This opens up an cluster of interesting questions of relevance for the explanatory project, and especially for the proposal offered in section 5 , which is based on the idea that both attention and consciousness are correlated with informational enhancement. I will come back to these studies in that section.

\footnotetext{
${ }^{14}$ Relatedly, it was previously argued that attention and consciousness had opposite effects on afterimage duration: more attention to a stimulus appeared to decrease afterimage strength and duration while increasing stimulus visibility produced a corresponding increase on these dimensions (Koch \& Tsuchiya, 2007; Van Boxtel et al., 2010a). However, recent evidence shows that attention and consciousness both increase afterimage duration (Travis et al., 2017).
}

Lopez, A. (2022). Vicarious attention, degrees of enhancement, and the contents of consciousness. Philosophy and the Mind Sciences, 3, 1. https://doi.org/10.33735/phimisci.2022.9194 


\subsection{Double dissociation and independence}

Finally, there is a good body of neuroscientific research supporting a double dissociation between attention and consciousness. A double dissociation means that consciousness can occur without attention, and attention can occur without consciousness. Thus, the studies discussed in this section go beyond those discussed in sections 3.1 and 3.2, which only support a single dissociation. Notably, a double dissociation between attention and consciousness does not entail that they always occur without the other, which is clearly false. Nonetheless, it does entail that attention and consciousness are largely independent processes.

For starters, attention and consciousness are associated with different underlying cortical activation patterns (Chica et al., 2016; Nani et al., 2019; Webb et al., 2016) and with different temporal structures (Davidson et al., 2018; Fiebelkorn \& Kastner, 2020). The two of them also exhibit different MEG and EEG profiles. MEG revealed a correlation between stimulus visibility and mid-gamma activity for a sustained period (250-500ms) in the occipital cortex. In contrast, attention correlated with high-gamma activity in the parietal cortex at a slightly later point (350-500ms) (Wyart \& Tallon-Baudry, 2008). ${ }^{15}$ In turn, EEG revealed greater responses for consciously perceived stimuli than for non-perceived stimuli, regardless of whether the stimuli were attended or not (Chica et al., 2010; Forschack et al., 2017). Furthermore, the EEG components of attention have been observed for both visible and invisible cues (Travis et al., 2019).

It has also been argued, on neuroscientific grounds, that there is an intrinsic aspect of phenomenal consciousness for which attention does not and cannot account, namely, the first-person perspective (Tallon-Baudry et al., 2018). ${ }^{16}$ While attention can provide the contents of a conscious state, it cannot provide the egocentric reference frame necessary for subjectively experiencing these contents. ${ }^{17}$ This element must be provided by a separate process: the internal monitoring of bodily states, specifically, the monitoring of visceral input from the heart and the gut. $^{18}$

A double dissociation has also been advocated from a more theoretical standpoint, based on considerations about the separate evolution of attention and consciousness (Haladjian \& Montemayor, 2015; Montemayor \& Haladjian, 2015). Montemayor and Haladjian argue that although there is some overlap between the two processes, represented in the kind of processing that they call conscious attention, there are also many primitive forms of selective attention that do not re-

\footnotetext{
${ }^{15} \mathrm{Mid}$-gamma: 54-64Hz; high-gamma: 76-90Hz.

${ }^{16} \mathrm{I}$ am thankful to a reviewer from this journal for bringing this research to my attention.

${ }^{17}$ Despite the similarity of this characterization to what I called reflective consciousness above, the authors do not intend to single out this specific kind of consciousness. On their account, the first-person perspective is an essential component of phenomenal consciousness.

${ }^{18}$ Evidence favoring this view includes observations that heartbeat evoked response correlates with the self-relevance of the thoughts that a subject is currently entertaining, associated activity in brain areas independently correlated with the self, and studies of the experience of body ownership.
} 
quire consciousness of the phenomenal kind. These include spatial attention and feature-based attention, and the slightly higher-level object-based attention, all of which aid animals in spatial navigation and detection of relevant environmental stimuli (Haladjian \& Montemayor, 2015). ${ }^{19}$ Furthermore, the authors also point out that most conceptual theories of consciousness entail that there are forms of consciousness that do not require selective attention. For example, the distinction between phenomenal and access consciousness (Block, 1995) entails such a dissociation. If phenomenal consciousness is sometimes not accompanied by access consciousness, then phenomenal consciousness may sometimes not be accompanied by attention (Montemayor \& Haladjian, 2015, p. 88). ${ }^{20}$ In this way, the authors' proposal goes beyond supporting a distinction between phenomenally conscious and phenomenally unconscious attention (a distinction the authors endorse): it also makes room for inattentive phenomenal consciousness.

To be sure, Montemayor and Haladjian acknowledge that some forms of selective attention are probably necessary for phenomenal consciousness. One example is cross-modal attention, which evolves out of the more primitive attentional forms like spatial, feature-based, or object-based attention. This kind of attention enables the kind of informational integration with an egocentric perspective that is essential for phenomenal consciousness. However, even if all forms of phenomenal consciousness involve selective cross-modal attention, there might still be some forms of phenomenal consciousness that do not require selective attention of other kinds. In this sense, one can say that phenomenal consciousness is independent of selective attention of these specific sorts.

Summing up, there is reason to think that selective attention and phenomenal consciousness must come apart along many dimensions, despite partial overlap and occasional co-occurrence. This is a stronger claim than the one supported by the discussion in section 3.3, which only states that attention and consciousness do come apart. Now it is time to consider the implications for the explanatory project, that is, the project of understanding of consciousness through the study of attention. As we saw, this project comprises three central questions, namely: (1) What is the relation between selective attention and phenomenal consciousness? (2) Can we learn what the contents of someone's phenomenal consciousness are if we know the targets of their attention? And finally (3) What can we learn about the contents of consciousness if we know the targets of attention?

\footnotetext{
${ }^{19}$ In their (2015) paper, the authors note that not all animals with these functions have conscious awareness. However, it is not clear whether this means that these animals lack phenomenal consciousness. The latter claim might be somewhat hasty, given the current methodological challenges for assessing the presence of this kind of consciousness. The former claim, on the contrary, seems plausible, if by* awareness* they mean something like what I above called reflective consciousness.

${ }^{20}$ Interestingly, Montemayor and Haladjian point out that even opponents of the phenomenal/access consciousness distinction, such as Daniel Dennett (2005), seem to be committed to dissociating selective attention and phenomenal consciousness (see the discussion in Montemayor \& Haladjian, 2015, pp. 88-89).
} 


\subsection{Taking stock}

This quick overview suggests that (1) attention and consciousness are neither identical nor dependent on each other; in fact, each of them is a separate process that can occur without the other and can even hinder the other and (2) no, knowing which subset of information is selected and prioritized for further processing is not sufficient for knowing what the contents of someone's consciousness are. Selective attention to a target, be it endogenous or exogenous, and be it spatial, featurebased, or object-based, sometimes is and sometimes is not accompanied by a conscious experience of the attended thing. Moreover, there may be no principled way of mapping the former onto the latter, and it might well be that the two of them are separable as a matter of necessity. Hence, studying selective attention may not be of particular value for learning when information of things in the world becomes the content of a conscious experience. Another consequence is that theories like Attended Intermediate Representations theory and Global Workspace theory are mistaken, at least insofar as they are regarded as general theories of consciousness encompassing phenomenal consciousness. ${ }^{21}$

But what about (3)? Even if attention and consciousness are highly independent, can we not learn something about the contents of someone's conscious experience by knowing what things they are selectively attending to? In fact, there is reason to think that we can.

\section{Tying attention and consciousness back together}

As mentioned above, even a double dissociation is compatible with a partial overlap of selective attention and phenomenal consciousness. Indeed, the current evidence allows some forms of attention to be necessary for phenomenal consciousness, for instance, cross-modal attention (Haladjian \& Montemayor, 2015; Montemayor \& Haladjian, 2015). ${ }^{22}$ But if at least some forms of selective attention are necessary for phenomenal consciousness, and if there is a partial overlap between both kinds of processing, then it is possible to use selective attention as a guide into

\footnotetext{
${ }^{21}$ As noted above, some theorists have defended a version of Global Workspace theory that is explicitly construed as a theory of phenomenal consciousness (Raffone \& Pantani, 2010). It is also worth noting that Attended Intermediate Representations is not intended to be about selective attention. Prinz notes that his definition of attention can be extended to diffuse attention and processes like vigilance, alertness, and arousal (Prinz, 2012, p. 91). However, Prinz's characterization of attention (as a mechanism for making representations available for working memory encoding) does rely on the idea that attended information is information selected and prioritized for preferential processing.

${ }^{22}$ Note that one of the virtues of Haladjian and Montemayor's arguments for this claim is that, being based on considerations about the evolution of different brain areas and functions, they can bypass the methodological challenges for the behavioral and neuroscientific assessment of consciousness in the absence of attention (discussed in section 3.2).
}

Lopez, A. (2022). Vicarious attention, degrees of enhancement, and the contents of consciousness. Philosophy and the Mind Sciences, 3, 1. https://doi.org/10.33735/phimisci.2022.9194

(c) (1) ( The author(s). https://philosophymindscience.org ISSN: 2699-0369 
phenomenal consciousness, provided that the conditions under which these two co-occur are carefully delimited. Borrowing Montemayor and Haladjian's terms, this project amounts to tracing the boundaries of conscious attention. These boundaries shall at least separate conscious attention from unconscious attention. An additional virtue would be that these boundaries also delimit conscious attention from inattentive consciousness, provided that the latter exists.

I propose that the current research on selective attention and phenomenal consciousness suggests that (1) they are not identical but are bound to co-occur in some specific cases, (2) no, knowing which subset of information is selected and prioritized for further processing is not sufficient for knowing what the contents of consciousness are because we also need to know whether the process of selection and prioritization is of the right kind, and (3) knowing which information is selected and prioritized and what kind of selection and prioritization is being used does tell us which things constitute the contents of conscious experience.

In the remainder of the paper, I will introduce a framework that will help us define the specific cases when attention and consciousness are bound to co-occur, thus tracing the boundaries of conscious attention. The following discussion is mainly focused on question (1), that is, in clarifying the relations between attention and consciousness.

My proposal can be summarized in four steps. First, it is a plausible consequence of the characterization of attention as a process of selection and prioritization that the selected information is enhanced within the relevant cognitive system. Second, information can be more or less enhanced: enhancement comes in degrees. Third, it might be possible to pin down a specific degree of enhancement such that, when information is enhanced to that degree, it becomes the content of a conscious experience. If we learn what that degree is, and if we can pin down the forms of attention that enhance information to that degree, we can rely on attention as a window into consciousness. Finally, it might also be possible to pin down a specific degree of enhancement such that reaching that degree is necessary for information to enter the contents of conscious experience.

Degrees of attention have been previously proposed as a promising framework for systematizing the relations between attention and consciousness. For example, on the empirical front, Michael Pitts and colleagues (2018) propose that different "amounts" of attention might give rise to different forms of attention, which might enable us to identify the forms of attention required for consciousness. They conceptualize these amounts of attention as points in a continuum that goes from zero to full attention and where a threshold for "minimal attention" can be identified. On the conceptual front, Daniel Stoljar (2019) construes attention as a graded kind of processing and proposes that there is an amount of attention such that, when that amount of attention is allocated to a target, the target becomes conscious. ${ }^{23}$

\footnotetext{
${ }^{23}$ To be sure, Stoljar uses this framework as a way of clarifying when content becomes access conscious. In his view, increasing the degree of attention marks the transition between content being merely disposed for rational use and being poised for such use. The latter defines access 
Initial empirical motivation for endorsing this kind of framework comes from the observations that attention and consciousness correlate with boosting effects on neuronal responses (see the studies on signal amplification cited at the end of section 2). It also comes from studies suggesting that attention has effects similar to increasing some perceptual dimensions, such as brightness or contrast (Carrasco \& Barbot, 2019; Fazekas \& Nanay, 2021; also see the studies on perceptual adaptation cited in section 3.1). Furthermore, the framework can accommodate the further finding that the response increases associated with consciousness are significantly greater than those associated with attention (Kouider et al., 2016), a finding that is sometimes thought to evince a dissociation between attention and consciousness (Maier \& Tsuchiya, 2021).

To be sure, adopting this framework requires an explanation of the findings suggesting that attention and consciousness have opposite effects (from section 3.3). It also requires a response to an argument presented by Catherine TallonBaudry (2012), which disputes the idea that signal amplification is a common mechanism for attention and consciousness. Both things can be done. However, this will require fleshing out the proposal some more.

\section{Degrees of enhancement ${ }^{24}$}

I will now offer a fuller elaboration of the enhancement framework. I start by clarifying the notions of informational enhancement and thresholds of enhancement, how these notions relate to similar proposals, and how they can be the basis for systematizing the relations between attention and consciousness (section 5.1). I then defend this framework from the objections identified above (sections 5.2 and 5.3) and from an additional objection (section 5.4). Finally, I conclude this part by highlighting a crucial assumption for defusing the discussed counterexamples: sometimes, attention is allocated vicariously. This idea will be the focus of the final section of this paper (section 6).

\subsection{Degrees of enhancement, amounts of attention and measures of integration}

I said that the conception of attention as a process for selecting and prioritizing information entails that attended information is enhanced. However, I have not yet explained what I mean by this notion. ${ }^{25}$ As I understand it, enhancement is a higher-order property that information has when some first-order properties are

consciousness. I thank an anonymous reviewer from this journal for bringing this proposal to my consideration.

${ }^{24}$ I am thankful to two anonymous reviewers for their valuable suggestions, from which the discussion in this section has greatly benefitted.

${ }^{25}$ I offer further discussion on the notion of informational enhancement elsewhere (Lopez, 2020). 
present, in virtue of which the organism can make better use of that information. Some of those first-order properties include perceptual dimensions like detail, determinacy, precision, or vividness. They also include computational properties, such as facilitation and suppression effects at the neuronal level. Indeed, suppression of responses to non-target or distractor information is sometimes necessary to optimize target information processing for the system's use. ${ }^{26}$

One might think that enhancement is positively correlated with neuronal activity so that more neuronal activity corresponds to a higher degree of enhancement. This picture is suggested by many of the studies reviewed above, such as those evincing that attention amplifies stimulus signals (see section 2) and those evincing increased neuronal activity for task-relevant as opposed to task-irrelevant stimuli (section 3.2). ${ }^{27}$ However, there are some reasons not to be too hasty in endorsing this correlation. Notably, there are cases where attending to a stimulus might result in a decreased neuronal response, such as feature-based attention (Reynolds \& Heeger, 2009; Thiele \& Bellgrove, 2018). For example, a neuron hardwired to "prefer" upward motion might fire below baseline when presented with a stimulus moving downwards, and attention is directed to that stimulus (Martinez-Trujillo \& Treue, 2004). Characterizing enhancement as a higher-order property, rather than identifying it with a first-order property like neuronal spiking, enables us to bypass these difficulties. Firing below its baseline for its less preferred stimulus can be a way of conveying enhanced information of this stimulus' presence to neighboring neurons, thus biasing the competition more in favor of this stimulus.

Enhancement is essentially a comparative notion. For a piece of information to be enhanced, there must be a condition with respect to which the enhancement occurs. This condition might be the previous processing of the same piece of information or the processing of a different piece of information at the same time. It can also include both. For example, when you direct your attention to the pain in your leg, pain information is enhanced with respect to how that same information was processed a moment before and with respect to how other pieces of information are being processed at the same time (say, it becomes more enhanced than the information of the article that you are reading).

I have also proposed that two thresholds of informational enhancement might be distinguished: one is the threshold that information must reach in order to be consciously experienced at all, while the other one is the threshold that, when

\footnotetext{
${ }^{26}$ Because attention can inhibit processing in this way, one might think that boosting information past a threshold (as I suggest below) cannot be the only function of attention. Although the present account is compatible with a plurality of first-order functions, such as response boosting and inhibition, the proposal is that all of these first-level functions subserve the higher-order function of enhancing information. Even when attention elicits suppression effects, this is to aid in raising the degree of enhancement of some piece of information to a higher threshold. I take suppression effects to be related to enhancement in the same way as the firing below baseline discussed in the main text. I thank an anonymous reviewer from this journal for prompting me to clarify this point.

${ }^{27}$ For a defense of the view that attention is a signal amplifier, see Fazekas \& Nanay (2021).
} 
reached, guarantees that information will be consciously represented. Call these $\mathbf{T}^{-}$and $\mathbf{T}^{+}$, respectively. Now, given the characterization of enhancement as a comparative magnitude, $\mathbf{T}^{-}$and $\mathbf{T}^{+}$would be better characterized as relative rather than absolute values. Whether they are reached on a single occasion for a piece of information may thus strongly depend on what other information the system is processing at the moment. This can also be influenced by stimulus strength and background conditions (such as context) or global states of the system (such as level of arousal).

It is, of course, an empirical question whether our neurocognitive systems implement something like $\mathbf{T}^{-}$and $\mathbf{T}^{+}$, and how exactly these thresholds should be identified. That is, if enhancement is a measurable magnitude, determining which values or ranges of values of this magnitude correspond to $\mathbf{T}^{-}$and $\mathbf{T}^{+}$can only be determined empirically. Still, there is reason to think that this project is on the right track. There are at least two ways of starting to pin down these thresholds.

On the one hand, the proposal by Pitts and colleagues (2018) mentioned in section 4 relies on the hypothesis that there are different "checkpoints" in information processing, which might separate conscious from unconscious attention (and indeed, also might separate kinds of consciousness, such as phenomenal vs. access consciousness). The authors use this framework to classify a selection of some recent studies exploring the relations between attention and consciousness, on the basis of the kind of attentional strategy that each of them demands, in combination with the kind of stimulus used and its presentation conditions. See a graphic illustration of their proposal in figure 1.

In this picture, $\mathbf{T}$ - could be pinned down at the intersection of cells 1 and 2, while $\mathbf{T}+$ could be pinned down at the intersection between 5 and 6 .

The proposal that there are degrees of enhancement that are either necessary or sufficient for phenomenal consciousness and that are given by relative thresholds is also congenial in spirit to a prominent theoretical approach to the study of consciousness, namely, Integrated Information theory (IIT). According to IIT, a system becomes conscious when it reaches the maximum integration level of the information processed by its parts (Oizumi et al., 2014; Tononi et al., 2016). Very roughly, information is integrated when it has an irreducible causal profile. This occurs when the information carried by the whole system cannot be reduced to the sum of the information carried by the system's parts so that information carried by the whole generates causal effects that the sum of the information carried by the parts cannot generate. Information of the whole can also be causally affected in ways that need not be reflected in the information of the parts. A measure of the amount of informational integration in the system is symbolized as $\boldsymbol{\Phi}$. When $\boldsymbol{\Phi}$ has a positive value, the system can be regarded as conscious. Moreover, higher values of $\boldsymbol{\Phi}$ predict "more consciousness," or consciousness of more complex and sophisticated types.

Thus, a second way to pin down $\mathbf{T}+$ and $\mathbf{T}$ - could start by considering the relations of informational enhancement to informational integration. Some interest- 


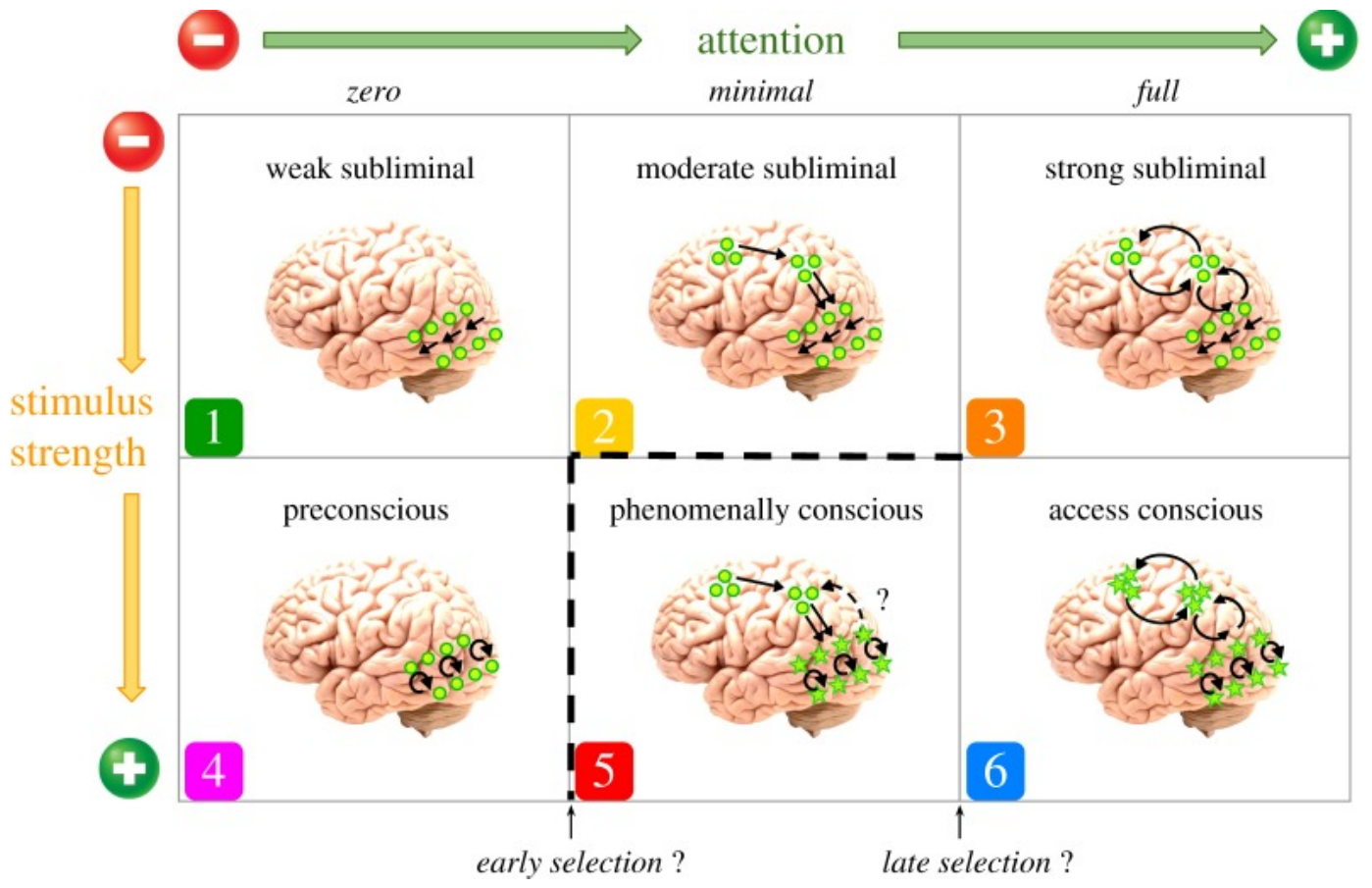

Figure 1: An expanded taxonomy of the relations between attention and consciousness. Different "checkpoints" in information processing lead up to more sophisticated forms of consciousness. The amount of attention allocated to the relevant stimuli defines some of these transitions and, importantly, the transition from pre-conscious to phenomenally conscious states. Republished with permission of The Royal Society (U.K.) from "The relationship between attention and consciousness: An expanded taxonomy and implications for 'no-report' paradigms"; Pitts, M. A., Lutsyshyna, L. A., \& Hillyard, S. A.; Philosophical Transactions of the Royal Society of London B: Biological Sciences, 37(1755), Copyright 2018; permission conveyed through Copyright Clearance Center, Inc.

ing interactions might arise. For starters, one might propose that $\mathbf{T}+$ is the same measure as a positive $\boldsymbol{\Phi}$ since both signal the point where conscious processing appears. Along these lines, one might think that degrees of enhancement are just amounts of integration, such that more enhanced information is more integrated information, or vice-versa. Note, however, that T- cannot be straightforwardly correlated with a degree of integration since IIT conceptualizes integration as sufficient for consciousness. In other words, once information is integrated, even if the measure of integration is very low, the system counts as conscious, although its consciousness can be of a very basic kind. IIT thus predicts that there is no such a thing as integrated unconscious information. ${ }^{28}$ In contrast, enhancement is

\footnotetext{
${ }^{28}$ Against this prediction, Haladjian and Montemayor (2015) note that sometimes information is integrated outside of consciousness. On the other hand, it has also been argued that sometimes there is consciousness without integration (Brogaard et al., 2021). A supplementation of Inte-
} 
not like this: information can be enhanced below T-, and thus, there is enhanced unconscious information.

One possible way to go would be to characterize T- as the minimum degree of enhancement that information must reach to become integrated. Enhancement and integration will then come apart in this respect: enhancement is a magnitude that is necessary but not sufficient for phenomenal consciousness, whereas integration is a magnitude that is both necessary and sufficient. Alternatively, $\mathbf{T}$ - and $\mathbf{T}+$ might signal different amounts of $\boldsymbol{\Phi}$, such that information reaching $\mathbf{T}$ - gives rise to consciousness of more rudimentary forms (the ones corresponding to lower values of $\boldsymbol{\Phi}$ ), while information reaching $\mathbf{T}+$ gives rise to more sophisticated forms of consciousness (the ones corresponding to higher values of $\boldsymbol{\Phi}$ ).

Even if a further specification is still needed, the elements we have in hand already enable us to outline how the enhancement framework conceptualizes some cases of purported unconscious attention (from section 3.1) and inattentive consciousness (from section 3.2) in a way that supports the explanatory project. I mentioned at the end of section 3.1 that it would be nice to identify some features that characterize unconscious attention. I now propose that one such feature is that the relevant information fails to reach the higher threshold of enhancement $\mathbf{T}+$. In many of these cases, there are limiting factors for the amount of information that the organism can extract from the stimulus and the extent to which the system can use this information. Some of these factors are masks (Kentridge et al., 2008; Norman et al., 2013) or damage to cortical areas responsible for extracting specific kinds of stimulus information (Kentridge et al., 1999).

On the other hand, cases of purported inattentive consciousness can be tentatively characterized as cases where information of the relevant stimuli is enhanced at least up to $\mathbf{T}$-, while leaving it an open question whether the enhancement reaches $\mathbf{T}+$ as well. Note that characterizing $\mathbf{T}+$ as sufficient for phenomenal consciousness does not entail that lesser degrees of enhancement are never conscious. However, one might distinguish between conscious information above and below $\mathbf{T}+$ so that, for instance, the former is more elaborated, distinct, or sophisticated than the latter. So if we characterize information of "unattended" stimuli in partial report, dual-task, or crowding as enhanced above $\mathbf{T}$ - but not necessarily above $\mathbf{T}+$, we might count these contents as conscious, albeit this consciousness is of a lesser degree than the one for attended stimuli.

It is now time to address some potential empirical objections to the present proposal. Two of these objections were mentioned towards the end of section 4. The first is an argument from the opposing effects of selective attention and phenomenal consciousness. If attention is an information enhancer, and if consciousness requires a certain degree of enhancement, then why is it that in some cases, attention makes stimuli disappear faster or impairs perception, as in motioninduced blindness and Troxler fading, or the attentional blink? (see section 3.3).

grated Information theory with the enhancement framework could provide a way to accommodate these cases.

Lopez, A. (2022). Vicarious attention, degrees of enhancement, and the contents of consciousness. Philosophy and the Mind Sciences, 3, 1. https://doi.org/10.33735/phimisci.2022.9194

(c) (1) () The author(s). https://philosophymindscience.org ISSN: 2699-0369 
The second objection is Tallon-Baudry's (2012) observation that signal amplification might not be a common correlate for attention and consciousness, despite initial appearances. I will tackle these worries in reverse order.

\subsection{What if attention and consciousness amplify signals in different ways?}

Tallon-Baudry disputes the idea that the neural mechanisms used by attention are directly equivalent to those mediating contrast increases in the stimulus. Although attending to a stimulus has similar perceptual and behavioral effects than increasing its contrast (as evinced, for instance, in Carrasco et al., 2004, among other studies), she points out that these effects might be implemented in different ways at the neural level. To support this point, she cites studies that reveal an earlier peaking of neuronal responses in the monkey primary visual cortex when physical stimulus contrast is increased (Gawne et al., 1996). She then compares these results with those observed in MEG readings during spatial attention in humans (Hopf et al., 2006), which do not reveal such a temporal shift in neuronal responses. Furthermore, she mentions other studies which suggest that if spatial attention affects the temporal profile of neuronal responses at all, it must do it only at a later temporal point (after $200 \mathrm{~ms}$, which contrasts starkly with the $30-40 \mathrm{~ms}$ that it takes for the effects of increases in physical contrasts to manifest; see Noguchi et al., 2007). Finally, a direct comparison of the effects of contrast increases and spatial attention in monkey area V4 showed that although both factors affected the magnitude of single-cell responses, attention did not produce an earlier spiking (Lee et al., 2007).

Based on these findings, Tallon-Baudry argues that it is premature to identify something like "neural amplification" as a common mechanism for attention and consciousness. However, her proposal seems to be that there are fine-grained differences in how attentional modulations and manipulations of visibility affect neural responses, not that either the former or the latter fail to amplify neural responses. Sure, one could individuate neural mechanisms very finely so that different amplification mechanisms underpin attention and consciousness. But in any case, the proposal that consciousness requires reaching a threshold of enhancement does not require that a single mechanism underlies both attentional modulations and modulations in response to physical changes in the stimulus affecting the stimulus' visibility. Indeed, there might be a diversity of mechanisms constituting the first-order properties that underpin the higher-order property of enhancement.

\subsection{Why does attention sometimes make stimuli disappear from consciousness?}

Let us now consider how the enhancement framework can accommodate some of the effects of attention that seem to go against the idea that attention enhances information of a stimulus to make it more suitable for conscious experience. We

Lopez, A. (2022). Vicarious attention, degrees of enhancement, and the contents of consciousness. Philosophy and the Mind Sciences, 3, 1. https://doi.org/10.33735/phimisci.2022.9194

() (1) (c) The author(s). https://philosophymindscience.org ISSN: 2699-0369 
have three puzzling cases of this sort: motion-induced blindness, Troxler fading, and the attentional blink.

Motion-induced blindness and Troxler fading are perceptual effects that seem to occur due to hardwired information processing constraints. In both cases, a stimulus that remains physically present throughout disappears intermittently from perception. Motion-induced blindness occurs when a static stimulus becomes momentarily invisible due to the presence of a field of moving distractors (Bonneh et al., 2001; Schölvinck \& Rees, 2009). In turn, Troxler fading is the gradual disappearance of peripheral stimuli when the gaze remains rigidly fixated on an object for several seconds (Troxler, 1804). The puzzling observation is that purposefully directing attention to these stimuli facilitates their disappearance. This is especially problematic for two tenets of the enhancement framework, namely, that attending to a target enhances information of that target to a greater degree and that the higher the degree of enhancement, the most likely it is for a piece of information to enter the contents of a conscious experience. On the face of motion-induced blindness and Troxler fading, it looks like one of these tenets has to go: either attention is not an informational enhancer, or else degrees of enhancement do not correlate with consciousness. However, once we consider the cases more closely, we will see that they need not be inconsistent with either claim.

In the motion-induced blindness study by Marieke Schölvinck and Geraint Rees (2009), participants were instructed to press a key when they noted that one of two yellow dots disappeared. The yellow dots were presented behind a grid of rotating blue crosses. See figure 2 for illustration. ${ }^{29}$

Participants were prompted to focus their attention on either the right or the left dot while maintaining fixation on a center point. Once they noted that a dot disappeared, participants must press a different key indicating which of the two dots it was. The experimenters observed that attended dots were significantly more likely to be reported as disappearing. ${ }^{30}$

\footnotetext{
${ }^{29}$ See an animated version of the stimulus at: https://commons.wikimedia.org/wiki/File:MotionBl indnessf.gif\#/media/File:MotionBlindnessf.gif

${ }^{30}$ Interestingly, the second experiment in this study assessed the effect when attention was globally withdrawn from both the yellow dots and its rotating distractors by being engaged in a different task (detecting a stimulus in a rapid series presented at fixation). In this experiment, the motioninduced blindness display was presented in the upper-right quadrant of the visual periphery. Three conditions were examined: no attentional load, low attentional load, and high attentional load; these were defined by the difficulty of the central task. This experiment showed that the greater the attentional load, and thus the lesser the amount of attention that could be used for the motion-induced blindness task, the longer the yellow dot remained invisible. This suggests that attentional processing indeed has a role in making stimuli pop into conscious experience. Still, these results may need to be contrasted with those of the attentional blink studies discussed below, which evince improved visibility under peripheral task conditions (see footnote 34 for further discussion).
} 


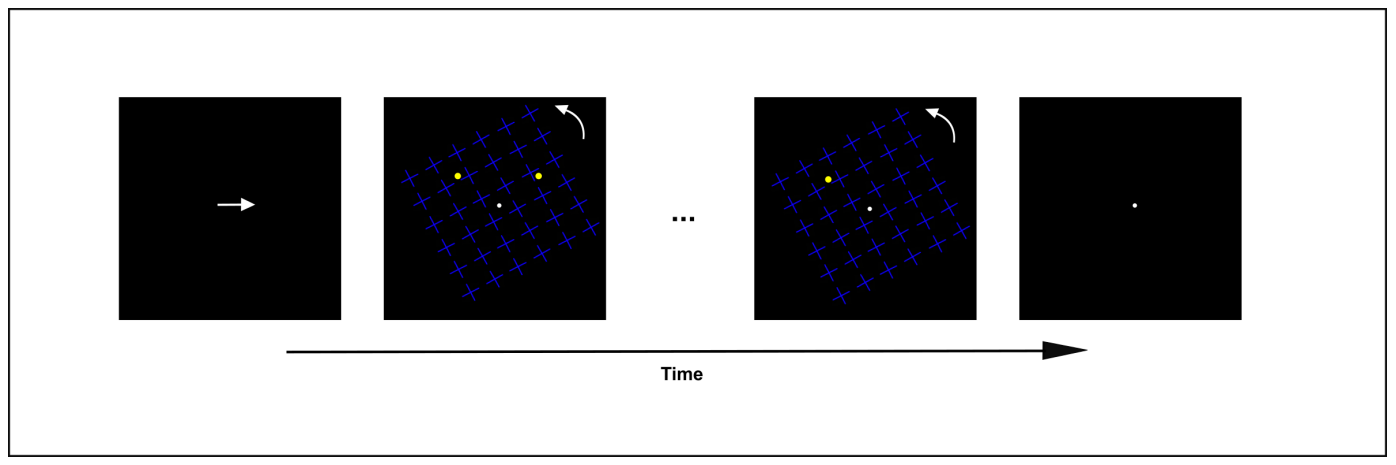

Figure 2: Testing attentional modulations of motion-induced blindness. A standard trial in Schölvinck and Rees' study started with an arrow cueing attention to the left or the right. Then, two yellow dots and a grid of rotating blue crosses appeared. Participants must maintain fixation and press a key when they noted the disappearance of one of the dots. Redrawn from fournal of Vision 9(1), 38, Schölvinck, M. L., and Rees, G., "Attentional influences on the dynamics of motioninduced blindness," 31-39, Copyright 2009, with permission from Association for Research in Vision and Ophthalmology.

According to the enhancement framework, when attention is directed to the yellow dot, information of this dot is enhanced to a higher degree than information of the unattended dot. The account also predicts that other things being equal, the attended dot should be consciously represented if the unattended one is. Schölvinck and Rees's findings falsify this prediction.

But importantly, other things are not equal. Directing attention to one of the dots not only enhances information of the dot; it also enhances information of the contextual cues that trigger the dot's disappearance as a result of hardwired processing constraints. Furthermore, one cannot neatly disentangle object-based attention from spatial attention. When you attend to the dot, you also attend to the dot's location. At that location, there is information of the moving grid; this information is also enhanced and computed for the generation of a conscious percept. Crucially, information of moving stimuli is prone to take over.

For one thing, it is beneficial for an organism to have information of the things that are moving around it, as this information might signal important changes in the environment correlated with food or danger. In contrast, information of a stationary and unchanging stimulus is not as prone to keep drawing on the organism's processing resources once it has been registered. To sum up: attending to the yellow dot also enhances some contextual information, which is more potentially significant and thus enhanced to a higher degree, trumping competing information in reaching the comparative threshold for conscious perception $\mathbf{T}+$.

This interpretation is in line with Schölvinck and Reese's account of their observations. They conceive motion-induced blindness as a completion process of the distracters into one homogeneous field, resulting in the target being hidden from 


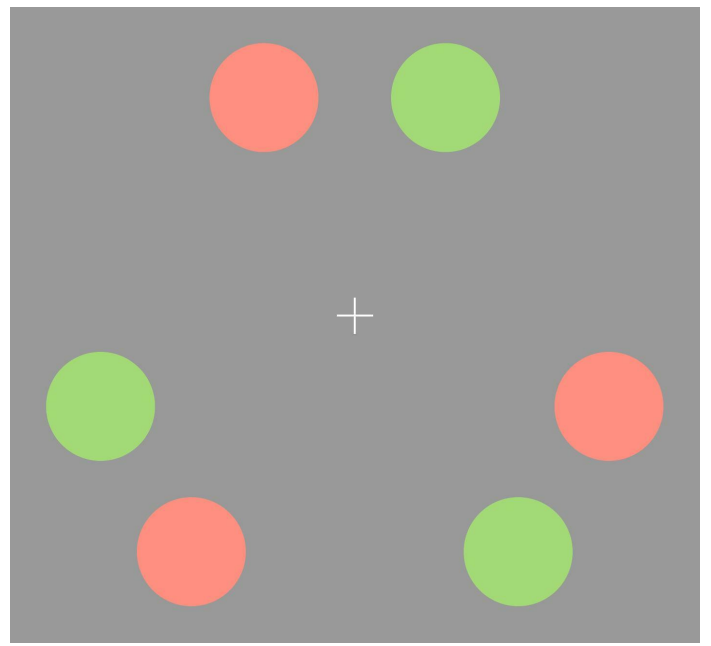

Figure 3: Testing attentional modulations of Troxler fading. In Lou's study, participants must direct their attention to either the green or the orange disks while maintaining fixation on the center and press a key to report the disappearance of a disk. Adaptation (in color) from Lou, L., Perception 28(4), p. 521, copyright @ 1999 by SAGE Publications. Reprinted by Permission of SAGE Publications.

view (Graf et al., 2002). Completion implies neural competition between target and distracters. Directing attention within the motion-induced blindness display "favors" the distracters by enhancing distracter field completion, inducing target disappearance.

Consider now Lianggang Lou's (1999) study of Troxler fading. Here, participants were instructed to attend to either the green or the orange disks in the periphery of a display while maintaining fixation on the center (see figure 3).

Participants' task was to press a key when at least one disk disappeared and keep it pressed until the disk appeared again. They were then asked how many disks of each color had disappeared. Lou observed that the attended disks were more likely to disappear first. ${ }^{31}$

Like motion-induced blindness, this effect creates trouble for the enhancement framework because this framework dictates that attending to a disk enhances information of that disk and that this information is more likely to become consciously represented than competing information. But in Lou's study, the opposite happened: attended information was more likely to go unconscious.

An important difference between this study and Schölvinck and Rees' is the type of attention each relies on. Schölvinck and Rees' study relies primarily on object-based attention: attention is directed on the basis of a stimulus with objectlike properties. In contrast, Lou's study relies primarily on feature-based attention: attention is directed on the basis of a property shared by several stimuli in

\footnotetext{
${ }^{31}$ Interestingly, color was a relevant factor: green attended disks disappeared first about $95 \%$ of the time, while orange ones disappeared first only about $68 \%$ of the time.
} 
the display, namely color. While object-based attention is usually constrained to enhance information from the specific location defined by the object's boundaries, feature-based attention is usually more evenly spatially distributed to bring out the relevant feature at any location where it is present.

That said, one crucial methodological aspect of Lou's study introduces an interesting interaction between feature-based and object-based attention. Participants in his study were encouraged to treat the three attended disks as forming a triangle, as this would facilitate attending to all three of them simultaneously. If participants followed the instruction, their attention was not singling out any particular disk during this task. Instead, their attention picked out the object constituted by the three disks sharing the same color. Accordingly, the enhanced information was information of this object as a whole, not information of any given single disk. This already lessens the worries for the enhancement framework: since there was no trial where all three disks disappeared, there was no trial where the enhanced object faded entirely from consciousness. ${ }^{32}$

Still, a worrisome aspect of this study is that the unattended disks remained visible throughout. On the face of it, this contradicts the prediction that these disks should be less likely to make it into consciousness. However, here, too, considerations about contextual conditions and hardwired constraints are relevant. Information of the three-disk object is being enhanced in a specific context, which involves peripheral presentation and particular ranges of luminance and contrast. ${ }^{33}$ It is plausible that information of the stimulus is not enhanced independently of this contextual information. Contextual information is also enhanced and included in the computations that determine what the conscious percept will be.

In addition to these considerations, there is also an alternative way of characterizing informational enhancement, accommodating both Schölvinck and Rees's and Lou's findings. On this alternative characterization, a piece of information is enhanced when its capacity to drive neuronal responses is boosted. Recall the case of feature-based attention making an "upward motion" neuron fire below its baseline when attention is directed to a stimulus moving downwards. We said that this pattern of firing conveys more information about the presence of a downward moving stimulus. One can also say that when attention is directed to the stimulus moving downwards, the capacity of this stimulus to drive the cell's response is boosted. The way the boost is expressed depends on how the cell typically responds to stimuli of this kind. For a neuron preferentially tuned for upward motion, information of downward motion presence is enhanced by suppression of firing. Analogously, enhancing the information of the yellow dot in the motion-induced blindness paradigm or information of the three-disk triangle in the Troxler fading paradigm means potentiating the responses that these stimuli would typically elicit. Since these responses involve momentary stimulus disappearance, it is expected that this effect is more likely to occur.

${ }^{32}$ On average, 1.2-1.4 disks disappeared per trial (depending on eccentricity).

${ }^{33}$ For Troxler fading to occur, the stimuli must be faint. 


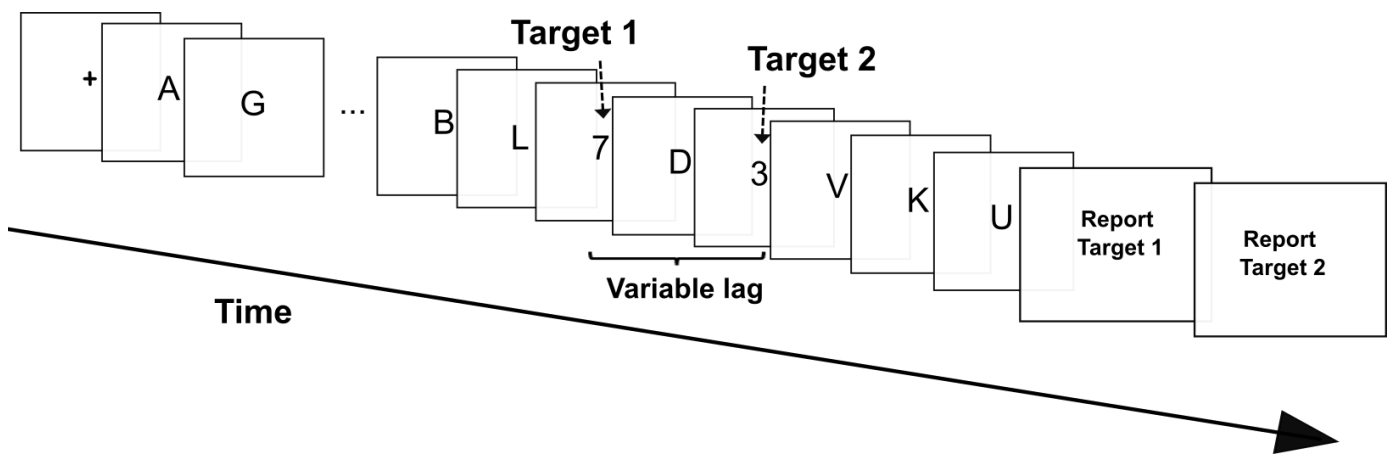

Figure 4: The attentional blink paradigm. Participants must report two targets appearing within a rapid succession of distractors, all presented at fixation. When the second target appears within 200-400ms after the first, participants fail to report it. This effect is known as the attentional blink.

These lines of explanation can also be extended to the remaining problem case, namely the attentional blink. The attentional blink is the inability to identify the second of two targets presented in rapid succession (Chun \& Potter, 1995; Olivers \& Nieuwenhuis, 2005; Raymond et al., 1992). Figure 4 depicts a standard paradigm for testing this effect.

The received explanation of the attentional blink is that the first target captures a great amount of attentional resources so that there is not a lot left for detecting the second. The effect is more pronounced when the lag between the two targets is shorter, which suggests that the "replenishment" of attentional resources after being used up in the first target takes some time. As noted above (section 2), this effect supports the idea that selective attention is necessary for conscious perception. When participants' selective attention has been exhausted, they fail to see the second target.

In the study by Christian Olivers and Sander Nieuwenhuis's (2005), the targets were two numbers presented within a string of letters. Remarkably, the experimenters found that detection of the second target improves when attention is drawn away from the target-detection task, This finding seems at odds with the enhancement framework. The framework predicts that when less attention is available for a target, that target is less likely to make it into consciousness. However, the study by Olivers and Nieuwenhuis suggests otherwise.

Once again, on a closer look, things need not be so. Note that the stimulus of interest is target 2. What is important is how much attention is available for enhancing this specific piece of information in every case. Fully engaging in the detection task enables the first target to use up all attention available so that there is no attention or insufficient attention for processing the second target. Contrastingly, performing a simultaneous unrelated task hinders the first target's salience, thus allowing that the overall balance of attention reaches the second target as well. Hence, what we are looking at when comparing a standard attentional blink 
paradigm with an attentional blink as a concurrent task is not a case where allocating less attention to a specific stimulus (i.e., locally) makes that stimulus more likely to enter consciousness. Although less attention is allocated to the overall task where the stimulus is embedded (i.e., globally), this setting favors that attention is distributed in a way that more attention is allocated to the stimulus of interest. $^{34}$

So far, I have explained how the three cases discussed can plausibly involve enhancing information so that the result is a conscious percept of the relevant information. In doing so, I have primarily focused on the facilitation effects that underpin enhancement. However, it is very likely that the suppression effects of attention also play an essential role in explaining these cases. ${ }^{35}$ Attention can inhibit responses to information other than its targets. This can happen synchronically or diachronically. For example, it is possible that in the attentional blink, the information of the second target is actively suppressed in order to encode the information of the first target better. If this were the case, then diverting attention away, as Olivers and Nieuwenhuis did, would reduce the active suppression effects, thus making the second target more likely to be consciously perceived. Similarly, it is possible that the attention-expedited Troxler fading and motion-induced blindness are partially due to the interactions between information whose processing is directly facilitated and information that is actively suppressed. ${ }^{36}$

\subsection{Attention and consciousness without enhancement?}

A final challenge for the degrees of enhancement framework is posed by effortless attention (Bruya, 2010; Montemayor \& Haladjian, 2015). ${ }^{37}$ In effortless attention, information seems to be processed without enhancement, at least in this sense: the distribution of attention seems flat, rather than having "peaks" for more at-

\footnotetext{
${ }^{34}$ As suggested in footnote 30 , it might be further illuminating to compare Olivers and Nieuwenhuis' results with those obtained in the second experiment in Schölvinck \& Rees (2009), where embeddedness in a peripheral task diminished stimuli visibility. The account given in the main text could also explain this apparent conflict: in Schölvinck and Rees' experiment, making the relevant task peripheral plausibly diminished the amount of attention available for the stimulus of interest (compared to the amount available when the task is central). Notably, in this experiment, both tasks were in the same modality (visual), whereas in the Olivers and Nieuwenhuis study, they were not. While the detection task was visual and was indeed presented at the center of the visual field, the concurrent tasks were either "mental" (engaging in free associations on task-irrelevant topics) or auditory (listening to music).

${ }^{35}$ This possibility was brought to my consideration separately by Slawa Loev and an anonymous reviewer from this journal. I am thankful to both of them.

${ }^{36} \mathrm{~A}$ further example of this interaction between facilitation and suppression is multiple-object tracking (for instance, in Pylyshyn, 2004; Pylyshyn, 2006; see also Alvarez \& Scholl, 2005). As an anonymous reviewer from this journal has kindly pointed out, active suppression of non-target information plausibly plays a role in the subjects' ability to isolate their targets in this paradigm. Thus, target information is enhanced partly due to the inhibition of non-target information.

${ }^{37}$ I thank an anonymous reviewer from this journal for bringing this case to my consideration.
} 
tended stimuli. ${ }^{38}$ If enhancement requires the peaks, that is, if it requires greater attention on some parts of the sensory input than others, then effortless attention would be attention without enhancement. Furthermore, if effortless attention is accompanied by phenomenal feelings (as it plausibly is), then there is phenomenal consciousness without enhancement. ${ }^{39}$

One initial response to this challenge is that the enhancement framework is primarily intended to capture selective attention. Effortless attention, on the other hand, might not be of the selective type. However, the case remains of interest for the more overarching project of extending the enhancement framework to account for attention and its relations with phenomenal consciousness more generally, beyond just the selective types of attention.

\subsection{Wrapping up}

In this section, I have argued that the enhancement framework is explanatorily useful, empirically well-motivated, and even consistent with evidence that initially seemed to contradict it directly. It also provides us with conceptual guidelines for approaching the daunting body of empirical literature from a systematic point of view.

In the final section of this paper, I will elaborate on one assumption that I have made in my treatment of the paradoxical effects of attention. I suggested that in many cases, it is not easy to disentangle different targets of attentional enhancing, for example, an object and the location the object is sitting in (especially if the object is static). I take this to support the idea that attending to some targets often involves enhancing information of things other than these targets alone so that attentional benefits can be observed for things other than the selected targets. I will now offer some more elaboration of this idea and some initial conceptual and empirical support.

\section{Vicarious attention}

"Vicarious attention" is the term that I will use to refer to attentional allocations that "come for free" when our attention is directed at a given target. For example, suppose that you are focusing your attention on a dark spot on the wall. By the same act, you are also allocating attention to a specific location in space, and the properties present there. Alternatively, suppose that you are sitting at a noisy café, and then your attention is suddenly captured by the sound of your name. ${ }^{40}$ By the same act, your attention is allocated to other things, such as the region where the voice came from or the voice's pitch. I propose that when the sound of your

\footnotetext{
${ }^{38}$ I borrow these suggestive terms from Watzl (2017).

${ }^{39}$ Similar considerations may apply to mind wandering (see footnote 49).

${ }^{40}$ This is the cocktail-party effect (Cherry, 1953; Moray, 1959; Treisman, 1969), which reveals that stimuli of great significance are preferentially processed even with very little attention. I thank an anonymous reviewer for pointing this out to me.
} 
name captures your attention or when you purposefully focus your attention on the dark spot on the wall, your attention also becomes allocated to the locations and properties of these stimuli. In attending to the dark spot on the wall, you also attend to these things, albeit indirectly. ${ }^{41}$ In this sense, you are attending vicariously to these things.

Conceptual and empirical considerations support the idea that attention behaves in this way. Prominently, Robert Kentridge (2011) has argued that a distinction between attending to an object and attending to the object's spatial location is not theoretically useful. Suppose that $\mathrm{O}$ is an object sitting at location L. Kentridge argues that there is no substantial difference in attention-related benefits between allocating attention directly to $\mathrm{O}$ and allocating attention to $\mathrm{O}$ by allocating attention to L. He argues that absent good grounds for drawing a distinction, we should believe that attending to a spatial location is sufficient for attending to an object at that location. His view seems to be that there is nothing more to attending to a location than enhancing the representations of the things present there. The notion of vicarious attention enables us to accommodate these insights without collapsing spatial and object-based attention. The idea that there is no substantive distinction between the two of them is captured by the proposal that both targets can be picked out with a single act of attending, in which one of them is primarily targeted and the other one benefits from this allocation vicariously. On spatial-based allocations, attended locations are the primary targets, whereas, on object-based allocations, the primary targets are the attended objects.

Behavioral studies suggest that the function of spatial attention is to enhance goal-specific properties of stimuli falling in the attended space, since attending to a spatial region typically produces enhanced processing of properties of objects falling within that region, rather than of properties of space per se (Kentridge, 2011; Remington \& Folk, 2001). Furthermore, Kentridge argues that this point is also supported by studies showing that attention alters the perceived properties of objects, such as perceived contrast and perceived hue (Carrasco et al., 2004). These studies show that spatial attention does more than speeding responses to items presented in a spatial location: it improves the processing of these objects by improving the processing of their properties.

This picture is further supported by neuroscientific studies suggesting that attending to an object produces attentional benefits for all its features, regardless of whether these are required for the task at hand. For example, in a study by O'Craven, Downing and Kanwisher (1999), attention was directed to one of two superimposed images (a house or a face), one of which was slowly oscillating. As expected, there was increased activity in the brain areas dedicated to the attended stimulus type (the para-hippocampal place area, or the fusiform face area, respectively). However, activity was also observed in the area of the brain that encodes motion when the attended stimulus was oscillating, even though these oscillations were task-irrelevant.

\footnotetext{
${ }^{41}$ One might use the "in virtue of" language to capture these relations: vicarious attention occurs in virtue of attention being allocated to something else.
} 

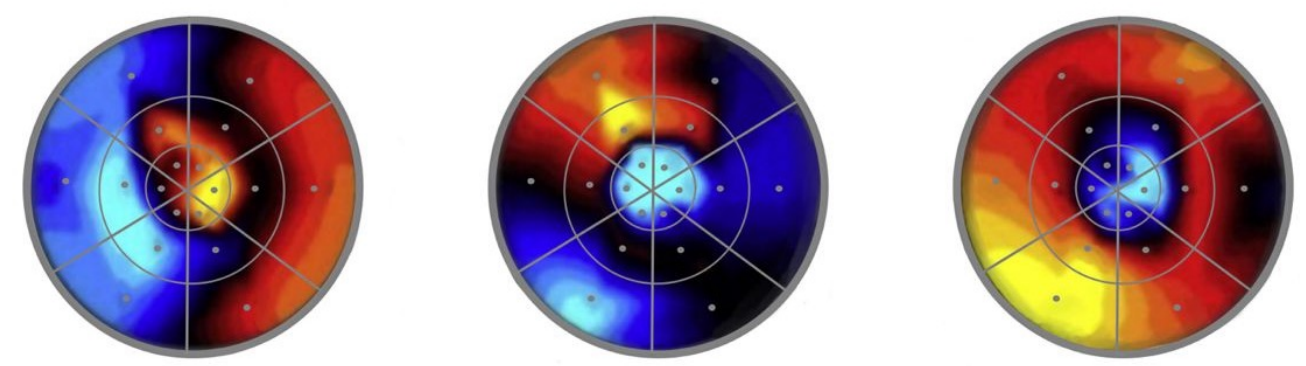

Figure 5: Excerpts from Datta and DeYoe's "library" of attentional distributions. Attending to one section of the visual field brings about attentional benefits for neighboring and non-neighboring regions. Yellow and red indicate increased neuronal activity in the areas of medial occipital visual cortex encoding each of the eighteen sections in Datta and DeYoe's stimulus grid, when participants were directing their attention to sections 6, 9 and 17, respectively (from left to right). Yellow indicates greater benefits. Adapted from Vision Research, May 49 (10), Datta, R. and E. A. DeYoe, "I know where you are secretly attending! The topography of human visual attention revealed with fMRI." 1037-1044, Copyright (2009), with permission from Elsevier. Many thanks to Zara Morgue for creating this figure.

Finally, a study by Ritobrato Datta and Edgar A. DeYoe (2009) on the topography of visual attention shows that attending to a specific region in the visual field gives rise to attentional effects beyond that region. Indeed, the attentional benefits spread over other regions that were not purposely attended themselves. ${ }^{42}$ Datta and DeYoe presented participants with a stimulus grid that divided their visual field into eighteen regions within 28 visual degrees around fixation. ${ }^{43}$ They found that directing attention to one of these regions brought about increased activity in neurons coding for other regions as well, regardless of whether these other regions were immediately contiguous to the purposely attended regions. Figure 5 depicts some of their observations.

These findings strongly suggest that at any given time when attention is allocated to a stimulus, the total attentional distribution at that time is not exhausted by attention to that stimulus. More conservatively, Datta and DeYoe's results suggest that focused attention to a spatial location does not entail that this is the only visual field region that benefits from attention. Further, their findings also suggest that an organism's allocations of attention are not entirely constrained by voluntary control. Attention can spread over things or regions in space other than the intended target of attention. ${ }^{44}$

\footnotetext{
${ }^{42}$ Suppression effects for regions other than the attended one were also observed, as discussed below.

${ }^{43}$ See this grid in figure 4 from Datta \& DeYoe (2009).

${ }^{44}$ Datta and DeYoe's findings also illustrate the suppression effects that focally attending to a section of the visual field has on other sections (depicted in blue in the figure). These effects must be
} 
I have presented some motivation for the idea that attending to some targets often involves enhancing the information of things other than these targets alone. Hence, sometimes we attend to things vicariously, both in everyday life and in controlled lab settings. However, it remains an open question whether and how vicarious allocations of attention can be regimented. For the present discussion, what is important is to note that the notion of vicarious attention introduces a more fine-grained way of thinking about the stimuli that can and should become contents of consciousness. Therefore, this proposal qualifies the way we understand cases of unconscious attention (section 3.1) and especially inattentive consciousness (section 3.2).

Regarding unconscious attention, the notion of vicarious attention supports the idea that information of the relevant targets is enhanced to a lessened degree, insofar as many of these targets benefitted from attention only because participants were attending to something else. Thus, blindsight patients (Kentridge et al., 1999) succeed in attending to the unseen target only because they attend to a location in their blind field. ${ }^{45}$ Likewise, the color of a masked prime (Kentridge et al., 2008) is attended only because the location of the prime is attended, and masked objects (Norman et al., 2013) are attended only because a (visible) cue captures attention.

On the other hand, if attention can behave in the proposed ways, then cases of purported inattentive consciousness might involve more attention than initially thought. For instance, in partial report paradigms (Landman et al., 2003; Sperling, 1960), attention might be vicariously allocated to the non-cued stimuli in virtue of being directed at the cued ones. In turn, in crowding paradigms (Block, 2012), attention might be vicariously allocated to the middle items in virtue of being directed to the flankers.

Admittedly, much remains to be clarified about the notion of vicarious attention. For one thing, one might wonder how the distinction between vicarious attention and the kind of attention it piggybacks on (call it primary attention) interacts with other distinctions sometimes made in the attention literature. Two prominent examples are the distinction between selective and non-selective atten-

considered when regimenting the way attention is vicariously transferred from one spatial location to another. As an anonymous reviewer from this journal has pointed out, information from the suppressed regions might fail to enter consciousness if the suppression is sufficiently strong. Hence, attending to a spatial region will not always bring about enhancement benefits for neighboring regions, or at least not for all neighboring regions. Overall, these considerations further highlight the need for integrating suppression effects into our account of attention. Conceptualizing enhancement as a higher-order property that results from a combination of facilitation and suppression is a step in this direction.

${ }^{45}$ This proposal must be distinguished from the one previously advanced by Christopher Mole (2008a). According to Mole, blindsighters merely attend to target locations, not to the targets themselves. Thus, the attended thing (a spatial location) is not the same as the non-experienced thing (an object at that location). He then concludes that the case does not support a dissociation between targets of attention and contents of consciousness. Although to my lights this rationale is on the right track, the considerations just discussed tell against it.

Lopez, A. (2022). Vicarious attention, degrees of enhancement, and the contents of consciousness. Philosophy and the Mind Sciences, 3, 1. https://doi.org/10.33735/phimisci.2022.9194

(9) (1) (c) The author(s). https://philosophymindscience.org ISSN: 2699-0369 
tion and the distinction between spatially focused and spatially diffuse attention (Prettyman, 2014). ${ }^{46}$ One might think that vicarious attention is never selective or focused, at least in the sense that vicarious targets are by definition different from the targets purportedly attended. However, depending on how focused attention is defined, vicarious attention can sometimes be focused. When I focus my attention on the dark spot on the wall and thereby attend vicariously to its dark shade, this allocation may count as focused, if by focused we understand something like attention constrained to a local stimulus (as opposed to a global one), or attention constrained to a delimited sub-region of the visual field.

Some non-focal forms of attention that operate alongside focused attention will be vicarious by definition. For instance, consider the suggestion by Adrienne Prettyman (2014) that focused attention is often accompanied by a halo of spatially distributed or diffuse attention, which comes at no additional processing cost. ${ }^{47}$ Since this allocation "comes for free," it is vicarious by our count. However, diffuse attention does not need to be always vicarious. One might purposefully broaden the focus of attention: this happens, for instance, in open-monitoring meditation (Lutz et al., 2007).

Relatedly, one might wonder whether vicarious attention is a kind of spatial attention. One reason for thinking this is that vicarious targets often spatially overlap or are spatially contiguous with the targets they piggyback. However, one reason not to characterize vicarious attention as essentially spatial from the start is that it has the profile of feature-based attention in some cases. For example, a spatial cue might vicariously direct attention to a specific color, and information of that color becomes enhanced at other locations as well. ${ }^{48}$

I have suggested that lack of purposefulness might be a way to define when a target is vicarious. If one is attending to $\mathrm{X}$ but not on purpose, then one is attending to X vicariously. Nonetheless, this idea might need to be revised in the light of effortless attention. To borrow an example from Montemayor and Haladjian (2015): if you are deeply engrossed in writing a novel, your attention is engaged in this action but in a way that does not involve subjectively felt effort. Although the action of writing the novel is purposeful, one might also say that attention is not purposefully directed to the objects involved (say, the keyboard and the screen) or to the action itself. Does this mean that effortless attention is vicarious? My initial answer is that insofar as writing the novel is an intentional action, any attention used to carry it out is not vicarious. However, the way we attend to the objects involved in the action (the keyboard and the screen) might as well be vicarious. ${ }^{49}$

\footnotetext{
${ }^{46}$ See also Prettyman (2021).

${ }^{47}$ Prettyman suggests that this halo of diffuse attention might be responsible for participants' performance in the dual-task paradigm (see section 3.2). Thus, although peripheral stimuli are processed without focused attention, they are not processed independently of attention.

${ }^{48}$ This happens in the (2008) masked priming study by Kentridge and colleagues, where participants were cued to attend to the invisible prime's location, yet attentional benefits for the same color of the prime at other locations in the display were observed.

${ }^{49}$ Along these lines, one might also wonder how vicarious attention interacts with mind wandering. Like effortless attention, mind wandering plausibly involves a "flat" attentional distribution (see
} 
Task conditions are another way of determining when attention is vicarious. Generally, a task-irrelevant target will be a vicarious one. An interesting suggestion related to this point is that vicarious attention might pick out information that is not directly relevant for attention's functional role, for instance, high-level or conceptual information. In other words: when I attend to the apple on my desk, the information needed for the functional role of attention, that is, for enhancement, is seemingly information of color and shape, but maybe not the information that this is an apple. Yet, attending to the apple's low-level features might bring along enhancement of its more high-level features. Nonetheless, these roles might be reversed depending on task demands or contextual demands. For example, when your attention gets captured by the sound of your name, the attention you allocate to low-level features of this stimulus like pitch and timber piggybacks on your attention to its high-level semantic features.

The considerations offered in the preceding paragraphs are not intended to provide a complete and systematic characterization of vicarious attention. However, they can provide some guidelines for embarking on such a project. Importantly, a complete regimentation of vicarious attention might be the basis for a deeper understanding of the relations between the different layers of phenomenally conscious contents. ${ }^{50}$

section 5.4). However, unlike effortless attention, mind wandering is not associated with any specific activity (for example, writing a novel or dancing); instead, it is often characterized as task-unrelated thought (Smallwood \& Schooler, 2015; but see Irving, 2016 for dissent). Mindwandering might also be plausibly considered an attentionless state. Since it plausibly involves phenomenal consciousness, it qualifies as a potential case of inattentive consciousness that falls within the scope of the present proposal. Although I cannot discuss this case at length here, here are some inchoate considerations about some directions this discussion might take.

If mind wandering involves vicarious attention rather than being an attentionless state, then it would no longer exemplify inattentive consciousness. One reason to think that mind-wandering could involve vicarious attention is its lack of purposefulness. However, one worry with this proposal is that vicarious attention must piggyback on attention to some other target, and it is not clear what this target might be for mind wandering. On the other hand, vicarious attention might not be needed to defuse this kind of counterexample: one could conceptualize mind wandering as an unregulated and spontaneous succession of targets of attention, where each of these targets is the primary occupant of the organism's processing resources at a time (the view proposed in Christoff et al., 2016 seems to go along these lines).

I wish to thank Jennifer Windt for prompting me to think about this case.

${ }^{50}$ Here is a quick example for illustrating this project. When I look at the white rabbit in the yard, my visual experience has a layer constituted by distal stimulus properties and a layer constituted by what is phenomenally apparent to me. This second layer could remain the same even if the stimulus out there changed (for instance, if it was replaced by a robot rabbit that looks exactly like the real rabbit). Vicarious attention could capture the sense in which I am attending to the properties of the stimulus that are not necessarily reflected in my visual experience, such as being a rabbit vs. being a robot rabbit. 


\section{Concluding remarks: Back to the explanatory project}

The discussion in this paper has been motivated by an attempt to answer three questions: (1) What is the relation between phenomenal consciousness and selective attention?, (2) Can we know what the contents of phenomenal consciousness are, if we know what are the targets of attention?, and (3) What can we know about the contents of consciousness if we know the targets of attention? I have proposed that (1) the relation between phenomenal consciousness and selective attention is defined by informational enhancement: attention determines the degree of enhancement, and phenomenal consciousness arises when a threshold is reached. I also proposed that (2) to know what the contents of consciousness are, we need to know what information is enhanced and the degree to which that information is enhanced. Question (3), in turn, remains open. It is plausible that some things that about the contents of conscious experience will remain unknown even if we know everything there is to know about how attention is distributed. For instance, we might remain ignorant about what it feels like when that information is enhanced. Still, attention might provide a useful approximation to the scientific and objective investigation of the contents of phenomenal consciousness.

\section{Acknowledgments}

Writing this paper was possible thanks to a one-year research grant from the German Service for Academic Exchange (DAAD). I am most thankful to Ophelia Deroy for hosting me and advising me during this time, as well as to my co-workers at the CVBE's research group at the Ludwig Maximilian University of Munich, not only for their interdisciplinary input and the rich and stimulating research environment they create but also for their various support as I adjusted to life in a new country: Oriane Armand, Bahador Bahrami, Lucas Battich, Lenka Gorman, Jurgis Karpus, Anita Keshmirian, Slawa Loew, Louis Longin, Sofiia Rappe, Zahra Rezazadeh, Anna Strasser, Justin Sulik, Paul Taylor, Mark Wulff Carstensen, and Jimena Zapata. I am also most thankful to Berit Brogaard for the many illuminating discussions on the ideas in this paper and to E.J. Green, Magdalena BalcerakJackson, and Eli Chudnoff for their very appreciated written feedback. Many thanks to Edgar DeYoe, Michael Pitts, and Marieke Schölvinck for kindly granting their permission for presenting their figures here. Finally, I wish to extend special thanks to two anonymous referees from this journal for their careful comments on previous versions of the manuscript.

\section{References}

Alvarez, G. A., \& Scholl, B. J. (2005). How does attention select and track spatially extended objects? New effects of attentional concentration and amplification. Journal of Experimental Psychology: General, 134(4), 461-476. https://doi.org/10.1037/0096-3445.134.4.461

Andersen, S. K., \& Müller, M. M. (2010). Behavioral performance follows the time course of neural facilitation and suppression during cued shifts of feature-selective attention. Proceedings of the National Academy of Sciences, 107(31), 13878-13882. https://doi.org/10.1073/pnas.1002436107

Ansorge, U., Horstmann, G., \& Worschech, F. (2010). Attentional capture by masked colour singletons. Vision Research, 50(19), 2015-2027. https://doi.org/https://doi.org/10.1016/j.visres.2010.07.015

Lopez, A. (2022). Vicarious attention, degrees of enhancement, and the contents of consciousness.

Philosophy and the Mind Sciences, 3, 1. https://doi.org/10.33735/phimisci.2022.9194

(c) (1) () The author(s). https://philosophymindscience.org ISSN: 2699-0369 
Baars, B. J. (2002). The conscious access hypothesis: Origins and recent evidence. Trends in Cognitive Sciences, 6(1), 47-52. https://doi.org/10.1016/S1364-6613(00)01819-2

Baars, B. J. (2005). Global workspace theory of consciousness: Toward a cognitive neuroscience of human experience. In S. Laureys (Ed.), The boundaries of consciousness: Neurobiology and neuropathology (Vol. 150, pp. 45-53). Elsevier. https://doi.org/https://doi.org/10.1016/S0079-6123(05)50004-9

Bahrami, B., Carmel, D., Walsh, V., Rees, G., \& Lavie, N. (2008). Spatial attention can modulate unconscious orientation processing. Perception, 37(10), 1520-1528. https://doi.org/10.1068/p5999

Bahrami, B., Lavie, N., \& Rees, G. (2007). Attentional load modulates responses of human primary visual cortex to invisible stimuli. Current Biology, 17(6), 509-513. https://doi.org/10.1016/j.cub.2007.01.070

Bauer, M., Oostenveld, R., Peeters, M., \& Fries, P. (2006). Tactile spatial attention enhances gamma-band activity in somatosensory cortex and reduces low-frequency activity in parieto-occipital areas. The fournal of Neuroscience, 26(2), 490-501. https://doi.org/10.1523/JNEUROSCI.5228-04.2006

Block, N. (1995). On a confusion about a function of consciousness. Behavioral and Brain Sciences, 18(2), 227-247. https://doi.org/10.1017/S0140525X00038188

Block, N. (2007). Consciousness, accessibility, and the mesh between psychology and neuroscience. Behavioral and Brain Sciences, 30(5-6), 481-499. https://doi.org/10.1017/S0140525X07002786

Block, N. (2008). Consciousness and cognitive access. Proceedings of the Aristotelian Society, 108(1pt3), 289-317. https://doi.org/10.1111/j.1467-9264.2008.00247.x

Block, N. (2012). The grain of vision and the grain of attention. Thought: A fournal of Philosophy, 1(3), 170-184. https://doi.org/10.1002/tht3.28

Block, N. (2014). Rich conscious perception outside focal attention. Trends in Cognitive Sciences, 18(9), 445-447. https://doi.org/10.1016/j.tics.2014.05.007

Bonneh, Y. S., Cooperman, A., \& Sagi, D. (2001). Motion-induced blindness in normal observers. Nature, 411(6839), 798-801. https://doi.org/10.1038/35081073

Braun, J. (2007). Vision: Attending the invisible. Current Biology, 17(6), R202-3. https://doi.org/10.1016/j.cub.2007.01.039

Brogaard, B., Chomanski, B., \& Gatzia, D. E. (2021). Consciousness and information integration. Synthese, 198(3), 763-792. https://doi.org/10.1007/s11229-020-02613-3

Bronfman, Z. Z., Brezis, N., Jacobson, H., \& Usher, M. (2014). We see more than we can report: "Cost free" color phenomenality outside focal attention. Psychological Science, 25(7), 1394-1403. https://doi.org/10.1177/0956797614532656

Bruya, Brian. (2010). Effortless attention : A new perspective in the cognitive science of attention and action. MIT Press. https://public.ebookcentral.proquest.com/choice/publicfullrecord.aspx?p=3339135

Buzsáki, G., \& Draguhn, A. (2004). Neuronal oscillations in cortical networks. Science, 304(5679), 1926-1929. https://doi.org/10.1126/science.1099745

Carrasco, M. (2011). Visual attention: The past 25 years. Vision Research, 51(13), 1484-1525. https://doi.org/10.1016/j.visres .2011 .04 .012

Carrasco, M., \& Barbot, A. (2019). Spatial attention alters visual appearance. Current Opinion in Psychology, 29, 56-64. https://doi.org/10.1016/j.copsyc.2018.10.010

Carrasco, M., Ling, S., \& Read, S. (2004). Attention alters appearance. Nature Neuroscience, 7(3), 308-313. https://doi.org/10.1038/nn1194

Carruthers, P. (2000). Phenomenal consciousness: A naturalistic theory. Cambridge University Press. https://doi.org/10.101 7/CBO9780511487491

Chelazzi, L., Miller, E. K., Duncan, J., \& Desimone, R. (1993). A neural basis for visual search in inferior temporal cortex. Nature, 363(6427), 345-347. https://doi.org/10.1038/363345a0

Cherry, E. C. (1953). Some experiments on the recognition of speech, with one and with two ears. Fournal of the Acoustical Society of America, 25, 975-979. https://doi.org/10.1121/1.1907229

Chica, A. B., Bayle, D. J., Botta, F., Bartolomeo, P., \& Paz-Alonso, P. M. (2016). Interactions between phasic alerting and consciousness in the fronto-striatal network. Scientific Reports, 6, 31868. https://doi.org/10.1038/srep31868

Chica, A. B., Lasaponara, S., Lupiáñez, J., Doricchi, F., \& Bartolomeo, P. (2010). Exogenous attention can capture perceptual consciousness: ERP and behavioural evidence. NeuroImage, 51(3), 1205-1212. https://doi.org/10.1016/j.neuroimage.2010.03.002

Christoff, K., Irving, Z. C., Fox, K. C. R., Spreng, R. N., \& Andrews-Hanna, J. R. (2016). Mind-wandering as spontaneous thought: A dynamic framework. Nature Reviews Neuroscience, 17(11), 718-731. https://doi.org/10.1038/nrn.2016.113

Chun, M. M., \& Potter, M. C. (1995). A two-stage model for multiple target detection in rapid serial visual presentation. Journal of Experimental Psychology: Human Perception and Performance, 21(1), 109-127. https://doi.org/10.1037//00961523.21.1.109

Lopez, A. (2022). Vicarious attention, degrees of enhancement, and the contents of consciousness.

Philosophy and the Mind Sciences, 3, 1. https://doi.org/10.33735/phimisci.2022.9194

(c) (1) ( The author(s). https://philosophymindscience.org ISSN: 2699-0369 
Clark, A. (2013). Whatever next? Predictive brains, situated agents, and the future of cognitive science. Behavioral and Brain Sciences, 36(3), 181-204. https://doi.org/10.1017/S0140525X12000477

Cohen, M. A., Alvarez, G. A., \& Nakayama, K. (2011). Natural-scene perception requires attention. Psychological Science, 22(9), 1165-1172. https://doi.org/10.1177/0956797611419168

Cohen, M. A., Cavanagh, P., Chun, M. M., \& Nakayama, K. (2012). The attentional requirements of consciousness. Trends in Cognitive Sciences, 16(8), 411-417. https://doi.org/10.1016/j.tics.2012.06.013

Corbetta, M., \& Shulman, G. L. (2002). Control of goal-directed and stimulus-driven attention in the brain. Nature Reviews Neuroscience, 3(3), 201-215. https://doi.org/10.1038/nrn755

Datta, R., \& DeYoe, E. (2009). I know where you are secretly attending! The topography of human visual attention revealed with fMRI. Vision Research, 49, 1037-1044. https://doi.org/10.1016/j.visres.2009.01.014

Davidson, M. J., Alais, D., Boxtel, J. J. van, \& Tsuchiya, N. (2018). Attention periodically samples competing stimuli during binocular rivalry. Elife, 7. https://doi.org/10.7554/eLife.40868

De Brigard, F. (2010). Consciousness, attention and commonsense. Journal of Consciousness Studies, 17(9-10), 189-201. https://www.ingentaconnect.com/content/imp/jcs/2010/00000017/F0020009/art00006

De Weerd, P., Smith, E., \& Greenberg, P. (2006). Effects of selective attention on perceptual filling-in. fournal of Cognitive Neuroscience, 18(3), 335-347. https://doi.org/10.1162/089892906775990561

Dehaene, S., Changeux, J.-P., Naccache, L., Sackur, J., \& Sergent, C. (2006). Conscious, preconscious, and subliminal processing: A testable taxonomy. Trends in Cognitive Sciences, 10(5), 204-211. https://doi.org/10.1016/j.tics.2006.03.007

Dehaene, S., \& Naccache, L. (2001). Towards a cognitive neuroscience of consciousness: Basic evidence and a workspace framework. Cognition, 79(1-2), 1-37. https://doi.org/10.1016/s0010-0277(00)00123-2

Dehaene, S., Naccache, L., Cohen, L., Bihan, D. L., Mangin, J. F., Poline, J. B., \& Rivière, D. (2001). Cerebral mechanisms of word masking and unconscious repetition priming. Nature Neuroscience, 4(7), 752-758. https://doi.org/10.1038/89551

Dennett, D. C. (2005). Sweet dreams: Philosophical obstacles to a science of consciousness (Vol. 54, pp. 475-476). MIT Press.

Desimone, R., \& Duncan, J. (1995). Neural mechanisms of selective visual attention. Annual Review of Neuroscience, 18(1), 193-222. https://doi.org/10.1146/annurev.ne.18.030195.001205

Devue, C., Laloyaux, C., Feyers, D., Theeuwes, J., \& Brédart, S. (2009). Do pictures of faces, and which ones, capture attention in the inattentional-blindness paradigm? Perception, 38(4), 552-568. https://doi.org/10.1068/p6049

Doesburg, S. M., Kitajo, K., \& Ward, L. M. (2005). Increased gamma-band synchrony precedes switching of conscious perceptual objects in binocular rivalry. NeuroReport: For Rapid Communication of Neuroscience Research, 16(11), 11391142. https://doi.org/10.1097/00001756-200508010-00001

Driver, J. (1998). The neuropsychology of spatial attention. In Attention. (pp. 297-340). Psychology Press/Erlbaum (UK) Taylor \& Francis.

Egly, R., Driver, J., \& Rafal, R. D. (1994). Shifting visual attention between objects and locations: Evidence from normal and parietal lesion subjects. fournal of Experimental Psychology: General, 123(2), 161-177. https://doi.org/10.1037//0096-3445.123.2.161

Engel, A. K., \& Singer, W. (2001). Temporal binding and the neural correlates of sensory awareness. Trends in Cognitive Sciences, 5(1), 16-25. https://doi.org/10.1016/s1364-6613(00)01568-0

Engell, A. D., \& McCarthy, G. (2010). Selective attention modulates face-specific induced gamma oscillations recorded from ventral occipitotemporal cortex. Fournal of Neuroscience, 30(26), 8780-8786. https://doi.org/10.1523/JNEUROSCI.1575-10.2010

Faivre, N., \& Kouider, S. (2011). Multi-feature objects elicit nonconscious priming despite crowding. fournal of Vision, 11(3). https://doi.org/10.1167/11.3.2

Fazekas, P., \& Nanay, B. (2021). Attention is amplification, not selection. British fournal for the Philosophy of Science, 72(1), 299-324. https://doi.org/10.1093/BJPS/AXY065

Fiebelkorn, I. C., \& Kastner, S. (2020). Functional specialization in the attention network. Annual Review of Psychology, 71, 221-249. https://doi.org/10.1146/annurev-psych-010418-103429

Forschack, N., Nierhaus, T., Müller, M. M., \& Villringer, A. (2017). Alpha-band brain oscillations shape the processing of perceptible as well as imperceptible somatosensory stimuli during selective attention. The fournal of Neuroscience, 37(29), 6983-6994. https://doi.org/10.1523/JNEUROSCI.2582-16.2017

Fries, P. (2005). A mechanism for cognitive dynamics: Neuronal communication through neuronal coherence. Trends in Cognitive Sciences, 9(10), 474-480. https://doi.org/10.1016/j.tics.2005.08.011

Fries, P., Reynolds, J. H., Rorie, A. E., \& Desimone, R. (2001). Modulation of oscillatory neuronal synchronization by selective visual attention. Science, 291(5508), 1560-1563. https://doi.org/10.1126/science.1055465

Lopez, A. (2022). Vicarious attention, degrees of enhancement, and the contents of consciousness.

Philosophy and the Mind Sciences, 3, 1. https://doi.org/10.33735/phimisci.2022.9194

(c) () ( ) The author(s). https://philosophymindscience.org ISSN: 2699-0369 
Fuchs, I., Theeuwes, J., \& Ansorge, U. (2013). Exogenous attentional capture by subliminal abrupt-onset cues: Evidence from contrast-polarity independent cueing effects. Journal of Experimental Psychology: Human Perception and Performance, 39(4), 974-988. https://doi.org/10.1037/a0030419

Gawne, T. J., Kjaer, T. W., \& Richmond, B. J. (1996). Latency: Another potential code for feature binding in striate cortex. fournal of Neurophysiology, 76(2), 1356-1360. https://doi.org/10.1152/jn.1996.76.2.1356

Geng, H., Song, Q., Li, Y., Xu, S., \& Zhu, Y. (2007). Attentional modulation of motion-induced blindness. Chinese Science Bulletin, 52(8), 1063-1070. https://doi.org/10.1007/s11434-007-0178-0

Graf, E. W., Adams, W. J., \& Lages, M. (2002). Modulating motion-induced blindness with depth ordering and surface completion. Vision Research, 42(25), 2731-2735. https://doi.org/10.1016/s0042-6989(02)00390-5

Graziano, M. S. A. (2013). Consciousness and the social brain. Oxford University Press.

Graziano, M. S. A. (2019). Attributing awareness to others: The attention schema theory and its relationship to behavioural prediction. Fournal of Consciousness Studies, 26(3-4), 17-37. https://www.ingentaconnect.com/content/imp/jcs/2019/ 00000026/f0020003/art00002

Gross, J., Schnitzler, A., Timmermann, L., \& Ploner, M. (2007). Gamma oscillations in human primary somatosensory cortex reflect pain perception. PLoS Biology, 5(5), e133. https://doi.org/10.1371/journal.pbio.0050133

Gruber, T., Müller, M. M., Keil, A., \& Elbert, T. (1999). Selective visual-spatial attention alters induced gamma band responses in the human EEG. Clinical Neurophysiology, 110(12), 2074-2085. https://doi.org/10.1016/s1388-2457(99)00176-5

Haladjian, H. H., \& Montemayor, C. (2015). On the evolution of conscious attention. Psychonomic Bulletin and Review, 22(3), 595-613. https://doi.org/10.3758/s13423-014-0718-y

Haynes, J.-D., Driver, J., \& Rees, G. (2005). Visibility reflects dynamic changes of effective connectivity between V1 and fusiform cortex. Neuron, 46(5), 811-821. https://doi.org/10.1016/j.neuron.2005.05.012

Hesselmann, G., Hebart, M., \& Malach, R. (2011). Differential BOLD activity associated with subjective and objective reports during "blindsight" in normal observers. The fournal of Neuroscience, 31(36), 12936-12944. https://doi.org/10.1523/JN EUROSCI.1556-11.2011

Hopf, J.-M., Boehler, C. N., Luck, S. J., Tsotsos, J. K., Heinze, H.-J., \& Schoenfeld, M. A. (2006). Direct neurophysiological evidence for spatial suppression surrounding the focus of attention in vision. Proceedings of the National Academy of Sciences of the United States of America, 103(4), 1053. https://doi.org/10.1073/pnas.0507746103

Intriligator, J., \& Cavanagh, P. (2001). The spatial resolution of visual attention. Cognitive Psychology, 43(3), 171-216. https://doi.org/10.1006/cogp.2001.0755

Irving, Z. (2016). Mind-wandering is unguided attention: Accounting for the "purposeful" wanderer. Philosophical Studies, 173(2), 547-571. https://doi.org/10.1007/s11098-015-0506-1

Jackson-Nielsen, M., Cohen, M. A., \& Pitts, M. A. (2017). Perception of ensemble statistics requires attention. Consciousness and Cognition, 48, 149-160. https://doi.org/10.1016/j.concog.2016.11.007

James, W. (1890). The principles of psychology (Vol. 1). Dover Publications.

Jiang, Y., Costello, P., Fang, F., Huang, M., \& He, S. (2006). A gender- and sexual orientation-dependent spatial attentional effect of invisible images. Proceedings of the National Academy of Sciences, 103(45), 17048. https://doi.org/10.1073/pn as. 0605678103

Kahneman, D., Treisman, A., \& Gibbs, B. J. (1992). The reviewing of object files: Object-specific integration of information. Cognitive Psychology, 24(2), 175-219. https://doi.org/10.1016/0010-0285(92)90007-o

Kanai, R., Tsuchiya, N., \& Verstraten, F. A. J. (2006). The scope and limits of top-down attention in unconscious visual processing. Current Biology, 16(23), 2332-2336. https://doi.org/10.1016/j.cub.2006.10.001

Kastner, S., \& Ungerleider, L. G. (2000). Mechanisms of visual attention in the human cortex. Annual Review of Neuroscience, 23, 315-341. https://doi.org/10.1146/annurev.neuro.23.1.315

Kentridge, R. W. (2011). Attention without awareness : A brief review. In C. Mole, D. Smithies, \& W. Wu (Eds.), Attention: Philosophical and psychological essays (pp. 228-246). Oxford University Press.

Kentridge, R. W., Heywood, C. A., \& Weiskrantz, L. (1999). Attention without awareness in blindsight. Proceedings of the Royal Society B Biological Sciences, 266(1430), 1805-1811. https://doi.org/10.1098/rspb.1999.0850

Kentridge, R. W., Nijboer, T. C. W., \& Heywood, C. A. (2008). Attended but unseen: Visual attention is not sufficient for visual awareness. Neuropsychologia, 46(3), 864-869. https://doi.org/10.1016/j.neuropsychologia.2007.11.036

Kiefer, M., \& Brendel, D. (2006). Attentional modulation of unconscious "automatic" processes: Evidence from event-related potentials in a masked priming paradigm. Journal of Cognitive Neuroscience, 18(2), 184-198. https://doi.org/10.1162/ 089892906775783688

Kiefer, M., \& Martens, U. (2010). Attentional sensitization of unconscious cognition: Task sets modulate subsequent masked semantic priming. Fournal of Experimental Psychology: General, 139(3), 464-489. https://doi.org/10.1037/a0019561

Lopez, A. (2022). Vicarious attention, degrees of enhancement, and the contents of consciousness.

Philosophy and the Mind Sciences, 3, 1. https://doi.org/10.33735/phimisci.2022.9194

(c) (1) () The author(s). https://philosophymindscience.org ISSN: 2699-0369 
Kim, C.-Y., \& Blake, R. (2005). Psychophysical magic: Rendering the visible 'invisible.' Trends in Cognitive Sciences, 9(8), 381-388. https://doi.org/10.1016/j.tics.2005.06.012

Koch, C., Massimini, M., Boly, M., \& Tononi, G. (2016). Neural correlates of consciousness: Progress and problems. Nature Reviews Neuroscience, 17(5), 307-321. https://doi.org/10.1038/nrn.2016.22

Koch, C., \& Tsuchiya, N. (2007). Attention and consciousness: Two distinct brain processes. Trends in Cognitive Sciences, 11(1), 16-22. https://doi.org/10.1016/j.tics.2006.10.012

Kouider, S., Barbot, A., Madsen, K. H., Lehericy, S., \& Summerfield, C. (2016). Task relevance differentially shapes ventral visual stream sensitivity to visible and invisible faces. Neuroscience of Consciousness, 2016(1). https://doi.org/10.1093/ nc/niw021

Landman, R., Spekreijse, H., \& Lamme, V. A. F. (2003). Large capacity storage of integrated objects before change blindness. Vision Research, 43(2), 149-164. https://doi.org/10.1016/s0042-6989(02)00402-9

Lee, J., Williford, T., \& Maunsell, J. H. R. (2007). Spatial attention and the latency of neuronal responses in macaque area V4. The fournal of Neuroscience, 27(36), 9632-9637. https://doi.org/10.1523/JNEUROSCI.2734-07.2007

Li, F. F., VanRullen, R., Koch, C., \& Perona, P. (2002). Rapid natural scene categorization in the near absence of attention. Proceedings of the National Academy of Sciences of the United States of America, 99(14), 9596-9601. https://doi.org/10.1 073/pnas.092277599

Lopez, A. (2020). Information gating and the structure of consciousness [PhD thesis]. https://scholarship.miami.edu/discov ery/fulldisplay?context=L\&vid=01UOML_INST:ResearchRepository\&search_scope=Research\&tab=Research\&docid =alma991031524284802976

Lou, L. (1999). Selective peripheral fading: Evidence for inhibitory sensory effect of attention. Perception, 28(4), 519-526. https://doi.org/10.1068/p2816

Luck, S. J., Girelli, M., McDermott, M. T., \& Ford, M. A. (1997). Bridging the gap between monkey neurophysiology and human perception: An ambiguity resolution theory of visual selective attention. Cognitive Psychology, 33(1), 64-87. https://doi.org/10.1006/cogp.1997.0660

Luck, S., Woodman, G., \& Vogel, E. (2000). Event-related potential studies of attention. Trends in Cognitive Sciences, 4(11), 432-440. https://doi.org/10.1016/s1364-6613(00)01545-x

Lutz, A., Dunne, J. D., \& Davidson, R. J. (2007). Meditation and the neuroscience of consciousness. In P. D. Zelazo, M. Moscovitch, \& E. Thompson (Eds.), Cambridge handbook of consciousness (pp. 19-497). Cambridge University Press.

Lycan, W. G. (1996). Consciousness and experience (Vol. 72). MIT Press.

Macdonald, J. S. P., \& Lavie, N. (2008). Load induced blindness. Fournal of Experimental Psychology: Human Perception and Performance, 34(5), 1078-1091. https://doi.org/10.1037/0096-1523.34.5.1078

Mack, A., \& Clarke, J. (2012). Gist perception requires attention. Visual Cognition, 20(3), 300-327. https://doi.org/10.1080/ 13506285.2012.666578

Mack, A., \& Rock, I. (1998). Inattentional blindness. The MIT Press.

Maier, A., \& Tsuchiya, N. (2021). Growing evidence for separate neural mechanisms for attention and consciousness. Attention, Perception \& Psychophysics, 83(2), 558-576. https://doi.org/10.3758/s13414-020-02146-4

Martinez-Trujillo, J. C., \& Treue, S. (2004). Feature-based attention increases the selectivity of population responses in primate visual cortex. Current Biology, 14(9), 744-751. https://doi.org/10.1016/j.cub.2004.04.028

Matthews, J., Schröder, P., Kaunitz, L., Boxtel, J. J. A. van, \& Tsuchiya, N. (2018). Conscious access in the near absence of attention: Critical extensions on the dual-task paradigm. Philosophical Transactions of the Royal Society London B Biological Sciences, 373(1755). https://doi.org/10.1098/rstb.2017.0352

Melloni, L., Molina, C., Pena, M., Torres, D., Singer, W., \& Rodriguez, E. (2007). Synchronization of neural activity across cortical areas correlates with conscious perception. The fournal of Neuroscience, 27(11), 2858-2865. https://doi.org/10 .1523/JNEUROSCI.4623-06.2007

Mole, C. (2008a). Attention in the absence of consciousness? Trends in Cognitive Sciences, 12(2), 44; author reply 44-5. https://doi.org/10.1016/j.tics.2007.11.001

Mole, C. (2008b). Attention and consciousness. Journal of Consciousness Studies, 15(4), 86-104. https://www.ingentaconne ct.com/content/imp/jcs/2008/00000015/00000004/art00006

Montemayor, C., \& Haladjian, H. H. (2015). Consciousness, attention, and conscious attention. MIT Press.

Moran, J., \& Desimone, R. (1985). Selective attention gates visual processing in the extrastriate cortex. Science, 229(4715), 782-784. https://doi.org/10.1126/science.4023713

Moray, N. (1959). Attention in dichotic listening: Affective cues and the influence of instructions. The Quarterly fournal of Experimental Psychology, 11, 56-60. https://doi.org/10.1080/17470215908416289

Nagel, T. (1974). What is it like to be a bat? Philosophical Review, 83, 435-450.

Lopez, A. (2022). Vicarious attention, degrees of enhancement, and the contents of consciousness.

Philosophy and the Mind Sciences, 3, 1. https://doi.org/10.33735/phimisci.2022.9194

(c) (1) ( The author(s). https://philosophymindscience.org ISSN: 2699-0369 
Naghavi, H. R., \& Nyberg, L. (2005). Common fronto-parietal activity in attention, memory, and consciousness: Shared demands on integration? Consciousness and Cognition, 14(2), 390-425. https://doi.org/10.1016/j.concog.2004.10.003

Nani, A., Manuello, J., Mancuso, L., Liloia, D., Costa, T., \& Cauda, F. (2019). The neural correlates of consciousness and attention: Two sister processes of the brain. Frontiers in Neuroscience, 13, 1169. https://doi.org/10.3389/fnins.2019.01169

Noguchi, Y., Tanabe, H. C., Sadato, N., Hoshiyama, M., \& Kakigi, R. (2007). Voluntary attention changes the speed of perceptual neural processing. European fournal of Neuroscience, 25(10), 3163-3172. https://doi.org/10.1111/j.14609568.2007.05552.x

Norman, L. J., Heywood, C. A., \& Kentridge, R. W. (2013). Object-based attention without awareness. Psychological Science, 24(6), 836-843. https://doi.org/10.1177/0956797612461449

Norman, L. J., Heywood, C. A., \& Kentridge, R. W. (2015). Exogenous attention to unseen objects? Consciousness and Cognition, 35, 319-329. https://doi.org/10.1016/j.concog.2015.02.015

O'Craven, K. M., Downing, P. E., \& Kanwisher, N. (1999). fMRI evidence for objects as the units of attentional selection. Nature, 401(6753), 584-587. https://doi.org/10.1038/44134

Oizumi, M., Albantakis, L., \& Tononi, G. (2014). From the phenomenology to the mechanisms of consciousness: Integrated information theory 3.0. PLoS Computational Biology, 10(5), e1003588. https://doi.org/10.1371/journal.pcbi.1003588

Olivers, C. N. L., \& Nieuwenhuis, S. (2005). The beneficial effect of concurrent task-irrelevant mental activity on temporal attention. Psychological Science, 16(4), 265-269. https://doi.org/10.1111/j.0956-7976.2005.01526.x

Pelli, D. G. (2008). Crowding: A cortical constraint on object recognition. Current Opinion in Neurobiology, 18(4), 445-451. https://doi.org/10.1016/j.conb.2008.09.008

Petersen, S. E., \& Posner, M. I. (2012). The attention system of the human brain: 20 years after. Annual Review of Neuroscience, 35, 73-89. https://doi.org/10.1146/annurev-neuro-062111-150525

Pitts, M. A., Lutsyshyna, L. A., \& Hillyard, S. A. (2018). The relationship between attention and consciousness: An expanded taxonomy and implications for 'no-report' paradigms. Philosophical Transactions of the Royal Society London B Biological Sciences, 373(1755). https://doi.org/10.1098/rstb.2017.0348

Polonsky, A., Blake, R., Braun, J., \& Heeger, D. J. (2000). Neuronal activity in human primary visual cortex correlates with perception during binocular rivalry. Nature Neuroscience, 3(11), 1153-1159. https://doi.org/10.1038/80676

Posner, M. I. (1980). Orienting of attention. Quarterly fournal of Experimental Psychology, 32(1), 3-25. https://doi.org/10.1 $080 / 00335558008248231$

Posner, M. I., \& Petersen, S. E. (1990). The attention system of the human brain. Annual Review of Neuroscience, 13, 25-42. https://doi.org/10.1146/annurev.ne.13.030190.000325

Prettyman, A. (2014). Attention and conscious perception. [PhD thesis]. University of Toronto.

Prettyman, A. (2021). What is diffuse attention? Mind and Language. https://2a013fac-9cf9-4aa3-b07e-aff848aae421.filesus r.com/ugd/e09b7d_33fc1ad31deb4d408111d0a72a7a7ac0.pdf

Prinz, J. (2012). The conscious brain: How attention engenders experience. Oxford University Press USA.

Pylyshyn, Z. (2004). Some puzzling findings in multiple object tracking: I. Tracking without keeping track of object identities. Visual Cognition, 11(7), 801-822. https://doi.org/10.1080/13506280344000518

Pylyshyn, Z. W. (2006). Some puzzling findings in multiple object tracking (MOT): II. Inhibition of moving nontargets. Visual Cognition, 14(2), 175-198. https://doi.org/10.1080/13506280544000200

Raffone, A., \& Pantani, M. (2010). A global workspace model for phenomenal and access consciousness. Consciousness and Cognition: An International fournal, 19(2), 580-596. https://doi.org/10.1016/j.concog.2010.03.013

Raymond, J. E., Shapiro, K. L., \& Arnell, K. M. (1992). Temporary suppression of visual processing in an RSVP task: An attentional blink? Journal of Experimental Psychology: Human Perception and Performance, 18(3), 849-860. https://doi.org/10.1037//0096-1523.18.3.849

Raz, A., \& Buhle, J. (2006). Typologies of attentional networks. Nature Reviews Neuroscience, 7(5), 367-379. https://doi.org/ $10.1038 / \mathrm{nrn} 1903$

Reddy, L., Moradi, F., \& Koch, C. (2007). Top-down biases win against focal attention in the fusiform face area. Neuroimage, 38(4), 730-739. https://doi.org/10.1016/j.neuroimage.2007.08.006

Reddy, L., Reddy, L., \& Koch, C. (2006). Face identification in the near-absence of focal attention. Vision Research, 46(15), 2336-2343. https://doi.org/10.1016/j.visres.2006.01.020

Reddy, L., Wilken, P., \& Koch, C. (2004). Face-gender discrimination is possible in the near-absence of attention. fournal of Vision, 4(2), 4-4. https://doi.org/10.1167/4.2.4

Remington, R. W., \& Folk, C. L. (2001). A dissociation between attention and selection. Psychological Science, 12(6), 511-515. https://doi.org/10.1111/1467-9280.00394

Lopez, A. (2022). Vicarious attention, degrees of enhancement, and the contents of consciousness.

Philosophy and the Mind Sciences, 3, 1. https://doi.org/10.33735/phimisci.2022.9194

(c) (1) ( The author(s). https://philosophymindscience.org ISSN: 2699-0369 
Rensink, R. A., O’Regan, J. K., \& Clark, J. J. (1997). To see or not to see: The need for attention to perceive changes in scenes. Psychological Science, 8(5), 368-373. https://doi.org/10.1111/j.1467-9280.1997.tb00427.x

Ress, D., Backus, B. T., \& Heeger, D. J. (2000). Activity in primary visual cortex predicts performance in a visual detection task. Nature Neuroscience, 3(9), 940-945. https://doi.org/10.1038/78856

Ress, D., \& Heeger, D. J. (2003). Neuronal correlates of perception in early visual cortex. Nature Neuroscience, 6(4), 414-420. https://doi.org/10.1038/nn1024

Reynolds, J. H., \& Chelazzi, L. (2004). Attentional modulation of visual processing. Annual Review of Neuroscience, 27, 611-647. https://doi.org/10.1146/annurev.neuro.26.041002.131039

Reynolds, J. H., Chelazzi, L., \& Desimone, R. (1999). Competitive mechanisms subserve attention in macaque areas V2 and V4. The Journal of Neuroscience, 19(5), 1736-1753. https://doi.org/10.1523/JNEUROSCI.19-05-01736.1999

Reynolds, J. H., \& Heeger, D. J. (2009). The normalization model of attention. Neuron, 61(2), 168-185. https://doi.org/10.101 6/j.neuron.2009.01.002

Rosenthal, D. M. (1997). A theory of consciousness. In N. Block, O. J. Flanagan, \& G. Guzeldere (Eds.), The nature of consciousness. MIT Press.

Scharlau, I. (2002). Leading, but not trailing, primes influence temporal order perception: Further evidence for an attentional account of perceptual latency priming. Perception \& Psychophysics, 64(8), 1346-1360. https://doi.org/10.3758/bf03194777

Scharlau, I., \& Ansorge, U. (2003). Direct parameter specification of an attention shift: Evidence from perceptual latency priming. Vision Research, 43(12), 1351-1363. https://doi.org/10.1016/s0042-6989(03)00141-x

Scharlau, I., \& Neumann, O. (2003). Perceptual latency priming by masked and unmasked stimuli: Evidence for an attentional interpretation. Psychological Research, 67(3), 184-196. https://doi.org/10.1007/s00426-002-0116-3

Schölvinck, M. L., \& Rees, G. (2009). Attentional influences on the dynamics of motion-induced blindness. Fournal of Vision, 9(1), 38.1-9. https://doi.org/10.1167/9.1.38

Schurger, A., Cowey, A., Cohen, J. D., Treisman, A., \& Tallon-Baudry, C. (2008). Distinct and independent correlates of attention and awareness in a hemianopic patient. Neuropsychologia, 46(8), 2189-2197. https://doi.org/10.1016/j.neur opsychologia.2008.02.020

Schurger, A., Cowey, A., \& Tallon-Baudry, C. (2006). Induced gamma-band oscillations correlate with awareness in hemianopic patient GY. Neuropsychologia, 44(10), 1796-1803. https://doi.org/10.1016/j.neuropsychologia.2006.03.015

Schwitzgebel, E. (2007). Do you have constant tactile experience of your feet in your shoes? Or is experience limited to what's in attention? Journal of Consciousness Studies, 14(3), 5-35. https://www.ingentaconnect.com/content/imp/jcs /2007/00000014/00000003/art00001

Sergent, C., Ruff, C. C., Barbot, A., Driver, J., \& Rees, G. (2011). Top-down modulation of human early visual cortex after stimulus offset supports successful postcued report. fournal of Cognitive Neuroscience, 23(8), 1921-1934. https://doi. $\operatorname{org} / 10.1162 /$ jocn.2010.21553

Simons, D. J., \& Chabris, C. F. (1999). Gorillas in our midst: Sustained inattentional blindness for dynamic events. Perception, 28(9), 1059-1074. https://doi.org/10.1068/p281059

Singer, W., \& Gray, C. M. (1995). Visual feature integration and the temporal correlation hypothesis. Annual Review of Neuroscience, 18, 555-586. https://doi.org/10.1146/annurev.ne.18.030195.003011

Smallwood, J., \& Schooler, J. W. (2015). The science of mind wandering: Empirically navigating the stream of consciousness. Annual Review of Psychology, 66(1), 487-518. https://doi.org/10.1146/annurev-psych-010814-015331

Smithies, D. (2011). Attention is rational-access consciousness. In C. Mole, D. Smithies, \& W. Wu (Eds.), Attention: Philosophical and psychological essays (pp. 247-273). Oxford University Press.

Sperling, G. (1960). The information available in brief visual presentations. Psychological Monographs: General and Applied, 74(11), 1-29. https://doi.org/10.1037/h0093759

Stazicker, J. (2011). Attention, visual consciousness and indeterminacy. Mind and Language, 26(2), 156-184. https://doi.org/10.1111/j.1468-0017.2011.01414.x

Steriade, M., Nuñez, A., \& Amzica, F. (1993). A novel slow (<1 hz) oscillation of neocortical neurons in vivo: Depolarizing and hyperpolarizing components. The fournal of Neuroscience, 13(8), 3252-3265. https://doi.org/10.1523/JNEUROSCI. 13-08-03252.1993

Stoljar, D. (2019). In praise of poise. In A. Pautz \& D. Stoljar (Eds.), Blockheads! Essays on Ned Block's philosophy of mind and consciousness.

Tallon-Baudry, C. (2012). On the neural mechanisms subserving consciousness and attention. Frontiers in Psychology, 2, 397-397. https://doi.org/10.3389/fpsyg.2011.00397

Tallon-Baudry, C., Bertrand, O., Delpuech, C., \& Permier, J. (1997). Oscillatory gamma-band (30-70 hz) activity induced by a visual search task in humans. The fournal of Neuroscience, 17(2), 722-734. https://doi.org/10.1523/JNEUROSCI.1702-00722.1997

Lopez, A. (2022). Vicarious attention, degrees of enhancement, and the contents of consciousness.

Philosophy and the Mind Sciences, 3, 1. https://doi.org/10.33735/phimisci.2022.9194

(c) (1) (c) The author(s). https://philosophymindscience.org ISSN: 2699-0369 
Tallon-Baudry, C., Bertrand, O., Hénaff, M.-A., Isnard, J., \& Fischer, C. (2005). Attention modulates gamma-band oscillations differently in the human lateral occipital cortex and fusiform gyrus. Cerebral Cortex, 15(5), 654-662. https://doi.org/ 10.1093/cercor/bhh167

Tallon-Baudry, C., Campana, F., Park, H.-D., \& Babo-Rebelo, M. (2018). The neural monitoring of visceral inputs, rather than attention, accounts for first-person perspective in conscious vision. Cortex, 102, 139-149. https://doi.org/10.101 6/j.cortex.2017.05.019

Taylor, H., \& Sayim, B. (2018). Crowding, attention and consciousness: In support of the inference hypothesis. Mind \& Language, 33(1), 17-33. https://doi.org/10.1111/mila.12169

Thiele, A., \& Bellgrove, M. A. (2018). Neuromodulation of attention. Neuron, 97(4), 769-785. https://doi.org/10.1016/j.neur on.2018.01.008

Thut, G., Nietzel, A., Brandt, S. A., \& Pascual-Leone, A. (2006). Alpha-band electroencephalographic activity over occipital cortex indexes visuospatial attention bias and predicts visual target detection. The fournal of Neuroscience, 26(37), 9494-9502. https://doi.org/10.1523/JNEUROSCI.0875-06.2006

Tong, F., Nakayama, K., Vaughan, J. T., \& Kanwisher, N. (1998). Binocular rivalry and visual awareness in human extrastriate cortex. Neuron, 21(4), 753-759. https://doi.org/10.1016/s0896-6273(00)80592-9

Tononi, G., Boly, M., Massimini, M., \& Koch, C. (2016). Integrated information theory: From consciousness to its physical substrate. Nature Reviews Neuroscience, 17(7), 450-461. https://doi.org/10.1038/nrn.2016.44

Travis, S. L., Dux, P. E., \& Mattingley, J. B. (2017). Re-examining the influence of attention and consciousness on visual afterimage duration. Fournal of Experimental Psychology: Human Perception and Performance, 43(12), 1944-1949. https://doi.org/10.1037/xhp0000458

Travis, S. L., Dux, P. E., \& Mattingley, J. B. (2019). Neural correlates of goal-directed enhancement and suppression of visual stimuli in the absence of conscious perception. Attention, Perception \& Psychophysics, 81(5), 1346-1364. https://doi.org/10.3758/s13414-018-1615-7

Treisman, A. M. (1969). Strategies and models of selective attention. Psychological Review, 76(3), 282-299. https://doi.org/10.1037/h0027242

Treue, S. (2003). Visual attention: The where, what, how and why of saliency. Current Opinion in Neurobiology, 13(4), 428-432. https://doi.org/10.1016/S0959-4388(03)00105-3

Troxler, I. P. V. (1804). Über das Verschwinden gegebener Gegenstände innerhalb unseres Gesichtskreises. Ophthalmologische Bibliothek, 2(2), 1-53. https://www.worldcat.org/title/ophthalmologische-bibliothek/oclc/491712012

Tse, P. U. (2004). Mapping visual attention with change blindness: New directions for a new method. Cognitive Science, 28(2), 241-258. https://doi.org/10.1016/j.cogsci.2003.12.002

Tse, P. U., Martinez-Conde, S., Schlegel, A. A., \& Macknik, S. L. (2005). Visibility, visual awareness, and visual masking of simple unattended targets are confined to areas in the occipital cortex beyond human V1/V2. Proceedings of the National Academy of Sciences of the United States of America, 102(47), 17178-17183. https://doi.org/10.1073/pnas.0508010102

Tsuchiya, N., Wilke, M., Frässle, S., \& Lamme, V. A. F. (2015). No-report paradigms: Extracting the true neural correlates of consciousness. Trends in Cognitive Sciences, 19(12), 757-770. https://doi.org/10.1016/j.tics.2015.10.002

Van Boxtel, J. J. A., Tsuchiya, N., \& Koch, C. (2010a). Opposing effects of attention and consciousness on afterimages. Proceedings of the National Academy of Sciences of the United States of America, 107(19), 8883-8888. https://doi.org/10 .1073/pnas.0913292107

Van Boxtel, J., Tsuchiya, N., \& Koch, C. (2010b). Consciousness and attention: On sufficiency and necessity. Frontiers in Psychology, 1, 217. https://doi.org/10.3389/fpsyg.2010.00217

Van den Bussche, E., Hughes, G., Humbeeck, N. V., \& Reynvoet, B. (2010). The relation between consciousness and attention: An empirical study using the priming paradigm. Consciousness and Cognition, 19(1), 86-97. https://doi.org/10.1016/j. concog.2009.12.019

Vanduffel, W., Tootell, R. B., \& Orban, G. A. (2000). Attention-dependent suppression of metabolic activity in the early stages of the macaque visual system. Cerebral Cortex, 10(2), 109-126. https://doi.org/10.1093/cercor/10.2.109

Vidal, J. R., Chaumon, M., O’Regan, J. K., \& Tallon-Baudry, C. (2006). Visual grouping and the focusing of attention induce gamma-band oscillations at different frequencies in human magnetoencephalogram signals. fournal of Cognitive Neuroscience, 18(11), 1850-1862. https://doi.org/10.1162/jocn.2006.18.11.1850

Volz, L. J., \& Gazzaniga, M. S. (2017). Interaction in isolation: 50 years of insights from split-brain research. Brain, 140(7), 2051-2060. https://doi.org/10.1093/brain/awx139

Vuilleumier, P., Sagiv, N., Hazeltine, E., Poldrack, R. A., Swick, D., Rafal, R. D., \& Gabrieli, J. D. E. (2001). Neural fate of seen and unseen faces in visuospatial neglect: A combined event-related functional MRI and event-related potential study. Proceedings of the National Academy of Sciences, 98(6), 3495-3500. https://doi.org/10.1073/pnas.051436898

Lopez, A. (2022). Vicarious attention, degrees of enhancement, and the contents of consciousness.

Philosophy and the Mind Sciences, 3, 1. https://doi.org/10.33735/phimisci.2022.9194

(c) (1) ( The author(s). https://philosophymindscience.org ISSN: 2699-0369 
Watanabe, M., Cheng, K., Murayama, Y., Ueno, K., Asamizuya, T., Tanaka, K., \& Logothetis, N. (2011). Attention but not awareness modulates the BOLD signal in the human V1 during binocular suppression. Science, 334(6057), 829-831. https://doi.org/10.1126/science.1203161

Watzl, S. (2017). Structuring mind: The nature of attention and how it shapes consciousness. Oxford University Press.

Webb, T. W., Igelström, K. M., Schurger, A., \& Graziano, M. S. A. (2016). Cortical networks involved in visual awareness independent of visual attention. Proceedings of the National Academy of Sciences, 113(48), 13923-13928. https://doi.org/10.1073/pnas.1611505113

Wilke, M., Logothetis, N. K., \& Leopold, D. A. (2006). Local field potential reflects perceptual suppression in monkey visual cortex. Proceedings of the National Academy of Sciences, 103(46), 17507-17512. https://doi.org/10.1073/pnas.0604673103

Wolfe, J. M., Reinecke, A., \& Brawn, P. (2006). Why don't we see changes?: The role of attentional bottlenecks and limited visual memory. Visual Cognition, 14(4-8), 749-780. https://doi.org/10.1080/13506280500195292

Womelsdorf, T., \& Fries, P. (2007). The role of neuronal synchronization in selective attention. Current Opinion in Neurobiology, 17(2), 154-160. https://doi.org/10.1016/j.conb.2007.02.002

Worden, M. S., Foxe, J. J., Wang, N., \& Simpson, G. V. (2000). Anticipatory biasing of visuospatial attention indexed by retinotopically specific alpha-band electroencephalography increases over occipital cortex. The fournal of Neuroscience, 20(6), RC63. https://doi.org/10.1523/JNEUROSCI.20-06-j0002.2000

Wu, W. (2014). Attention. Routledge. https://doi.org/10.4324/9781315777603

Wu, W. (2017). Attention and perception: A necessary connection? In B. Nanay (Ed.), Current controversies in philosophy of perception (pp. 148-162). Routledge.

Wu, W. (2018). The neuroscience of consciousness. In E. N. Zalta (Ed.), The stanford encyclopedia of philosophy (Winter 2018). Metaphysics Reseach Lab, Stanford University. https://plato.stanford.edu/archives/win2018/entries/consciousnessneuroscience/

Wyart, V., \& Tallon-Baudry, C. (2008). Neural dissociation between visual awareness and spatial attention. The fournal of Neuroscience, 28(10), 2667-2679. https://doi.org/10.1523/JNEUROSCI.4748-07.2008

Wyart, V., \& Tallon-Baudry, C. (2009). How ongoing fluctuations in human visual cortex predict perceptual awareness: Baseline shift versus decision bias. The Journal of Neuroscience, 29(27), 8715-8725. https://doi.org/10.1523/JNEUROSC I.0962-09.2009

Zhao, T., Zhu, Y., Tang, H., Xie, R., Zhu, J., \& Zhang, J. H. (2019). Consciousness: New concepts and neural networks. Frontiers in Cellular Neuroscience, 13, 302. https://doi.org/10.3389/fncel.2019.00302

\section{Open Access}

This article is distributed under the terms of the Creative Commons Attribution 4.0 International License (https://creativecommons.org/licenses/by/4.0/), which permits unrestricted use, distribution, and reproduction in any medium, as long as you give appropriate credit to the original author(s) and the source, provide a link to the Creative Commons license, and indicate if changes were made. 